\title{
Oxidative Stress at the Crossroads of Aging, Stroke and Depression
}

\author{
Anwen Shao ${ }^{1, \#, *}$, Danfeng Lin ${ }^{2, \#}$, Lingling Wang ${ }^{2}$, Sheng $\mathrm{Tu}^{3}$, Cameron Lenahan ${ }^{4,5}$, Jianmin \\ Zhang ${ }^{1,6,7}$
}

${ }^{1}$ Department of Neurosurgery, Second Affiliated Hospital, School of Medicine, Zhejiang University, Zhejiang, China. ${ }^{2}$ Department of Surgical Oncology, Second Affiliated Hospital, School of Medicine, Zhejiang University, Zhejiang, China. ${ }^{3}$ State Key Laboratory for Diagnosis and Treatment of Infectious Diseases, Collaborative Innovation Center for Diagnosis and Treatment of Infectious Diseases, The First Affiliated Hospital, College of Medicine, Zhejiang University, Zhejiang, China. ${ }^{4}$ Burrell College of Osteopathic Medicine, Las Cruces, USA. ${ }^{5}$ Center for Neuroscience Research, School of Medicine, Loma Linda University, Loma Linda, CA, USA. ${ }^{6}$ Brain Research Institute, Zhejiang University, Zhejiang, China. ${ }^{7}$ Collaborative Innovation Center for Brain Science, Zhejiang University, Zhejiang, China.

[Received January 28, 2020; Revised February 18, 2020; Accepted February 25, 2020]

\begin{abstract}
Epidemiologic studies have shown that in the aging society, a person dies from stroke every 3 minutes and 42 seconds, and vast numbers of people experience depression around the globe. The high prevalence and disability rates of stroke and depression introduce enormous challenges to public health. Accumulating evidence reveals that stroke is tightly associated with depression, and both diseases are linked to oxidative stress (OS). This review summarizes the mechanisms of OS and OS-mediated pathological processes, such as inflammation, apoptosis, and the microbial-gut-brain axis in stroke and depression. Pathological changes can lead to neuronal cell death, neurological deficits, and brain injury through DNA damage and the oxidation of lipids and proteins, which exacerbate the development of these two disorders. Additionally, aging accelerates the progression of stroke and depression by overactive OS and reduced antioxidant defenses. This review also discusses the efficacy and safety of several antioxidants and antidepressants in stroke and depression. Herein, we propose a crosstalk between OS, aging, stroke, and depression, and provide potential therapeutic strategies for the treatment of stroke and depression.
\end{abstract}

Key words: oxidative stress, stroke, subarachnoid hemorrhage, intracerebral hemorrhage, depression, mitochondrial dysfunction, antioxidant, aging

\section{Introduction}

Epidemiologic studies demonstrate that $11 \%$ of the world's population is over 60 years of age and this percentage will double to about $22 \%$ by 2050 [1]. A significant percentage of older individuals develop one or more age-related diseases, which may include two leading diseases characterized by high incidence and disability: stroke [2] and depression [3]. Stroke is classified into ischemic stroke and hemorrhagic stroke; the latter consists of intracerebral hemorrhage (ICH) and subarachnoid hemorrhage ( $\mathrm{SAH}$ ). It is estimated that on average, a person died from stroke every 3 minutes and 42 seconds in 2016 [4]. Global Burden of Disease 2017 identifies stroke as the third leading cause of years of life lost and disability-adjusted life years [5, 6]. Between 2006

*Correspondence should be addressed to: Dr. Anwen Shao, Second Affiliated Hospital, School of Medicine, Zhejiang University, Hangzhou, Zhejiang, China. Email: 21118116@zju.edu.cn; anwenshao@sina.com;. \#These authors contributed equally to this work.

Copyright: () 2020 Shao A et al. This is an open-access article distributed under the terms of the Creative Commons Attribution License, which permits unrestricted use, distribution, and reproduction in any medium, provided the original author and source are credited. 
and 2016, the actual number of stroke deaths increased $3.7 \%$, although the age-adjusted mortality rate decreased $16.7 \%$ due to the large increase in the number of elderly people [4, 7]. Like stroke, another disease that affects a significant proportion of the population is depression, a psychiatric disorder characterized by inactivity and negative feelings of inadequacy. The 12-month prevalence of major depressive disorder (MDD) is about $6 \%$, while the lifetime risk of MDD is nearly $15-18 \%$ [810]. Moreover, older age is identified as a consistent and important risk factor for a worse prognosis. This phenomenon may be associated with the effect of cognitive impairment [3]. As the World Health Organization (WHO) predicted depression to be the leading cause of global burden by 2030, attention should be paid to depression treatment $[10,11]$.

Over the past two decades, studies have identified the role of OS in these two diseases. Recently, preclinical experiments and clinical trials have focused on studying the efficacy of antioxidants and combined therapy with antidepressants in stroke or depressed patients. We review the results of experiments within the last 5 years, providing a comprehensive and novel overview of this interesting field.

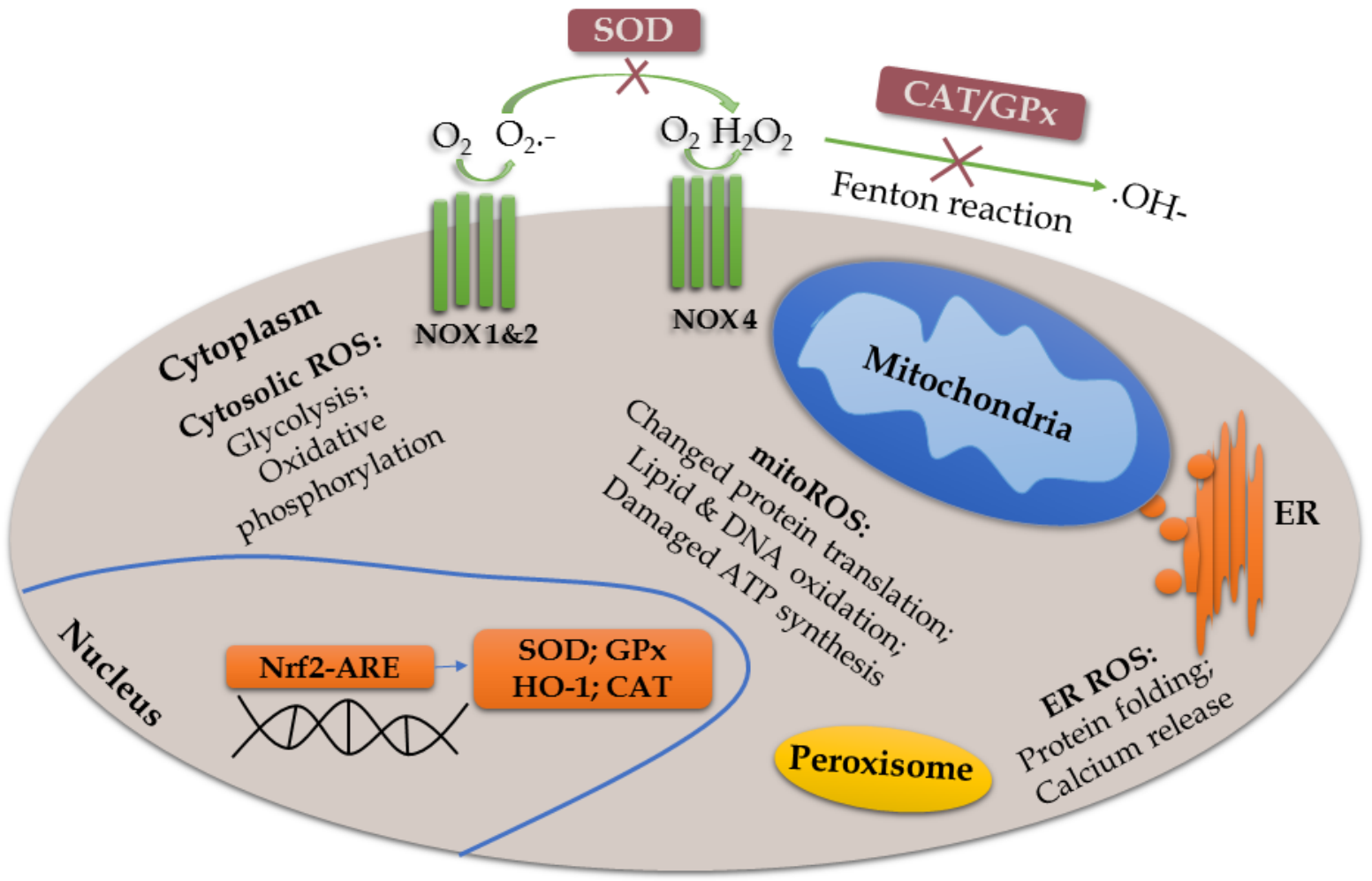

Figure 1. Schematic model of the main source of ROS and redox reaction. ROS are generated mainly from enzymatic reactions in the cytoplasm, endoplasmic reticulum, mitochondria, and peroxisome [300]. Specifically, overproduced mitoROS can affect metabolic pathways, such as alteration of protein translation, oxidation of lipid and DNA, and impairment of ATP synthesis [301]. Moreover, assembled NOX (NOX1 and NOX2) complex transports an electron from cytosolic NADPH to oxygen to form superoxide on the extracellular side [13]. The NOX4 complex rapidly converts the superoxide to $\mathrm{H}_{2} \mathrm{O}_{2}$, which undergoes a Fenton reaction to produce hydroxyl radicals and ions, and to regulate many downstream effects [302]. However, these oxidative events are inhibited by antioxidants, such as SOD and CAT/GPx. Activation of Nrf2-ARE pathway increases antioxidants, such as HO-1, SOD1, and CAT to protect cells from FR accumulation [303].

\section{Overview of oxidative stress and the antioxidant system}

OS describes a state in which the body produces excessive ROS and RNS in response to deleterious substances. Under normal conditions, OS and the anti-OS system are beneficial to physiological functions, such as respiration, circulation, etc. Mitochondrial dysfunction and internal environment disturbance can arise from multiple cellular molecules and signaling pathways as a result of imbalanced redox reactions, characterized by increased production of reactive oxygen species (ROS) and reactive nitrogen species (RNS) (Fig. 1), as well as decreased antioxidant defenses. The most important ROS are mitochondrial ROS (mitoROS) produced from enzymes of the mitochondrial respiratory chain. Overproduced mitoROS can affect metabolic pathways, leading to a compromised function of organelles [12]. Another 
significant source of ROS is NADPH oxidase (NOX). When the complex of NOX is assembled, it transports an electron from the cytosolic NADPH to oxygen to then form superoxide on the extracellular side [13]. The antioxidant system consists of enzymes and nonenzymatic substances, among which nuclear factor erythroid 2related factor (Nrf2) is the most important factor. Nrf2 is a transcription factor and can recognize the antioxidant response element (ARE) to regulate several genes, such as heme oxygenase 1 (HO-1). Activation of the Nrf2-ARE pathway increases antioxidants and protects the cells from free radical (FR) accumulation [14].

Under physiological conditions, moderate OS activity is necessary for body health. Toxic effects derived from ROS and RNS can be ameliorated or neutralized by FR scavengers and the antioxidant system. However, when a large number of ROS and RNS are generated, excessive FR then induce molecular oxidation, cell membrane modification, and enzyme inactivation, resulting in cellular damage and functional decline [15]. Overactive OS with an imbalanced redox state can induce many injuries, especially to the brain, partly expounding the role of OS in both stroke and depression.

\section{Overview of stroke and depression}

Ischemia-hypoxia often occurs in ischemic stroke, while intracerebral bleeding in the brain parenchyma can be found in ICH, and blood clots can be found in the subarachnoid space of SAH patients. Once cerebral ischemia occurs, it impairs cellular metabolism and triggers pathological pathways, such as immune responses, inflammatory reactions, OS, autophagy, and apoptosis, leading to irreversible neuronal damage and brain injuries accompanied by blood-brain barrier (BBB) disruption (Fig. 2) [16]. Particularly, the release of FR further damages the brain. Different from ischemia, both primary and secondary brain injury (SBI) occur in ICH and SAH. Mechanisms participating in post-ICH include the coagulation cascade (particularly thrombin), hemoglobin degradation, inflammation, apoptosis, necrosis, OS, and hematoma expansion [17]. Post-ICH events lead to SBI, which manifests as brain edema, BBB disruption, brain atrophy, vasospasm, neurological deficits, and even death [17]. Compared with ischemic stroke, the results of OS activity in the studies were similar in ICH. Indeed, this kind of behavior exhibited by OS also occurs in SAH [18]. Furthermore, brain injury involved in SAH is divided into two stages: an early stage within the first 72 hours, called early brain injury (EBI), and the delayed stage. OS plays a direct and indirect role in both stages, and many recent studies demonstrate efficacy of antioxidants in animal models, especially in EBI $[19,20]$.
In comparison with stroke, the main factors promoting MDD are psychosocial stressors, and the main pathophysiology of depression is associated with decreased monoamine levels, an altered hypothalamicpituitary-adrenal axis [21], inflammation [22], neuroplasticity and neurogenesis controlled by BDNF [22], and structural and functional brain changes (Fig. 2) [23, 24]. Apart from inflammation and neurogenesis, OS also plays a crucial role in depression. The role of OS in depression is supported by many studies that show upregulated OS activities and downregulated anti-OS responses [25-27]. In addition, the antioxidants may ease depressive symptoms [28, 29]. In summary, there is a close relationship between depression and OS.

As mentioned above, OS not only exists in stroke, but also occurs in depression. Moreover, many clinical trials have proved that stroke increases the incidence of depression, which inversely acts as an independent risk factor for stroke. On one hand, both ischemic and hemorrhagic stroke increases the prevalence of depression. A multicenter study found that approximately one-fifth of patients developed depression after stroke at a 12-month follow-up [30]. In addition, 757 patients with first-ever minor ischemic stroke were followed for one year and analysis showed that nearly $30 \%$ of patients developed depression [31]. However, the incidence rates of depression in ischemic stroke survivors aged 18-50 years and in the control group were $16.8 \%$ and $6.1 \%$, respectively [32]. A similar relationship is also seen in ICH [33] and SAH [34]. On the other hand, an Australian longitudinal study with a 12-year follow-up suggested that depression caused a 2-fold increase in the odds of stroke [35]. In addition, Pan did a meta-analysis consisting of 28 prospective cohort studies illustrating that the risk of ischemic stroke was exacerbated by depression [36], whereas another meta-analysis found that patients experiencing stressful life events had a $33 \%$ increased risk of total stroke [37] (Fig. 2).

\section{Roles of oxidative stress in stroke and depression}

Following ischemic stroke, an excess of ROS and RNS causes an ascending concentration of $\mathrm{H}^{+}$and $\mathrm{H}_{2} \mathrm{O}_{2}$, leading to DNA damage, endothelial impairment, and mitochondrial dysfunction (see below for details). Furthermore, they exacerbate the damage through OSmediated inflammation, apoptosis, autophagy, and the microbial-gut-brain axis. Apart from the mechanisms shown in ischemic stroke, the ROS and RNS, derived from the hemoglobin-heme-iron axis and activation of NOX, increase glutamate and inflammatory activities in $\mathrm{ICH}$, and they disrupt BBB integrity to influence EBI and $\mathrm{SBI}$ in SAH. It is unsurprising to find semblable outcomes and pathological processes of OS in depression. 


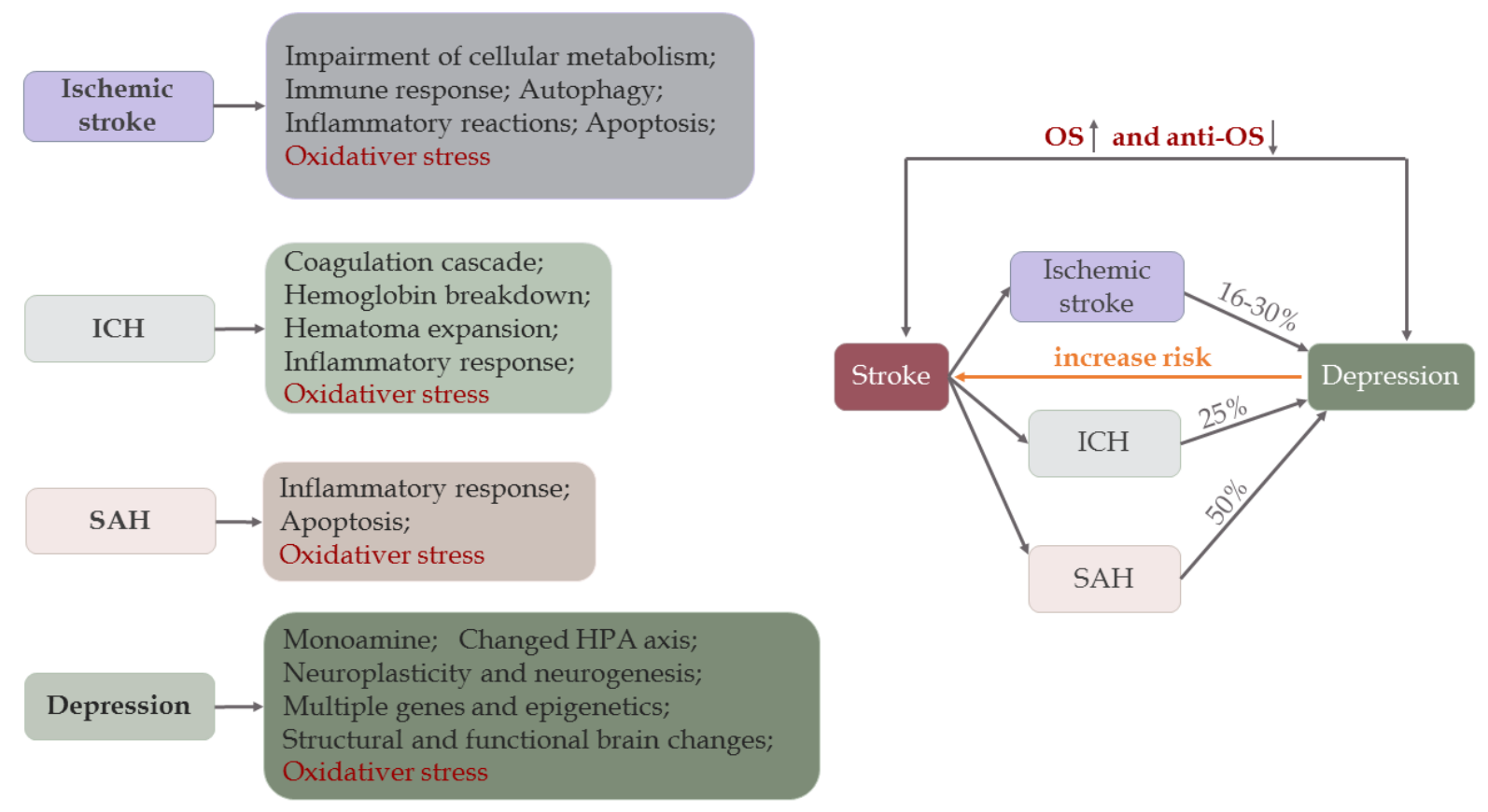

Figure 2. Pathogenesis and correlation between stroke and depression. There are different mechanisms in ischemic stroke [16], ICH [17], SAH [304], and depression [10]. Stroke and depression are associated with oxidative stress. Due to overactive OS activity and impaired anti-OS defenses, $16-30 \%$ of ischemic stroke survivors [31, 32], 25\% of ICH [33] patients, and 50\% of SAH [34] patients may develop depression later, but the age groups vary among studies. Conversely, depression increases the risk of stroke by $33 \%$ in patients who experience stressful life events [37].

\subsection{Oxidative stress in stroke and depression}

Because the human brain requires constant oxygen and nutrients to maintain its function, it is vulnerable to FR attack. The depletion of energy in ischemic stroke can cause a series of damage to promote the development or recurrence of stroke, and OS is involved in all stages of ischemic stroke progression (Fig. 3). Firstly, energy expenditure leads to the accumulation of $\mathrm{H}^{+}$concentration and $\mathrm{H}_{2} \mathrm{O}_{2}$. Studies on a mouse model of focal ischemia found that extracellular proton induce neuronal necroptosis via acid-sensing ion channel $1 \mathrm{a} /$ receptor interaction protein 1 association [38]. Secondly, ROS have effects on cerebral blood flow. ROS stimulates vasoconstriction and increases platelet aggregation and endothelial cell permeability, thereby affecting blood circulation [39]. Thirdly, RNS play a role in mitochondrial functions, such as reducing DNA and suppressing enzymes of the mitochondria. This is favored by a case-control study, in which a low mitochondrial DNA content in peripheral blood leukocytes is significantly related to ischemic stroke [40]. Lastly, ROS and RNS bring about DNA damage, protein destruction, lipid peroxidation, and cell death, leading to poor outcomes [41, 42]. The results of clinical studies have demonstrated that higher plasma levels of oxidized lowdensity lipoprotein reveal a worse prognosis [43], a higher prevalence of cognitive impairment [44], and an increased risk of death [45].

Hemorrhagic stroke is a common, serious neurological disease associated with high disability and mortality, especially when associated with ICH. One of the main underlying mechanisms is OS. ROS and RNS usually come from the metabolite axis of hemoglobinheme-iron, NOX activation, increased glutamate and inflammatory activities. Upon the onset of $\mathrm{ICH}$, bleeding into the brain parenchyma is commonly observed. Then, several biological events associated with hemoglobin oxidation and released iron occur, resulting in neurological damage (Fig. 4) [46, 47]. What's more, the results suggest that iron chelators could attenuate ROS generation to improve neurological function following $\mathrm{ICH}$, further supporting the hemoglobin-heme-iron axis [48]. Additionally, there are other mechanisms participating in the process of ICH, such as glial glutamate transporter responses [49] and mitochondria-dependent apoptosis [50]. The effects caused by other pathological events are similar to those in ischemic stroke $[51,52]$. Besides neuronal injuries, those pathological events contribute to SBI, including brain edema, BBB breakdown, and vasospasm. Interruption of the BBB facilitates ROS and RNS accumulation, which amplifies brain injuries [53]. 


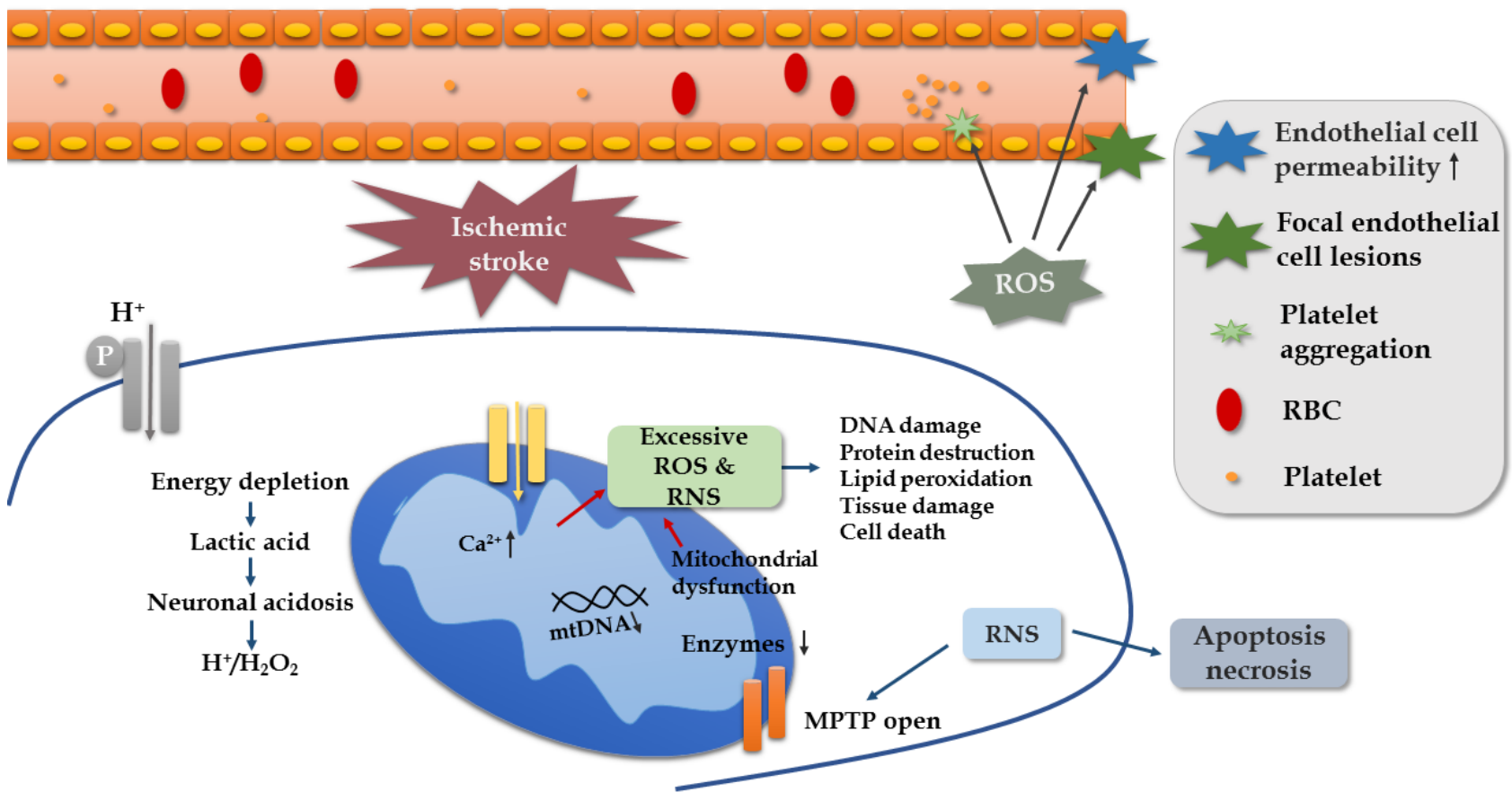

Figure 3. Mechanism of oxidative stress in ischemic stroke.

In SAH, EBI is identified as the immediate injury accompanied by subsequent events (brain edema, inflammation, apoptosis, etc.) in the first 72 hours, and EBI plays a vital role in the pathological processes (Fig. 4). After the occurrence of SAH, the intracranial pressure will rise to the pressure of the diastolic artery, which reduces cerebrospinal fluid pressure and disturbs cerebral autoregulation before BBB breakdown and occurrence of cerebral edema [54]. Due to erythrocytosis, the central nervous system (CNS) is exposed to high levels of $\mathrm{Hb}$ and $\mathrm{Hb}$-degradation products in the subarachnoid space. This pathological process produces excess ROS and RNS, and promotes cerebral vasospasm, cerebrovascular stenosis, and delayed cerebral ischemia [55]. Furthermore, several harmful events occur in SAH survivors, including altered ionic homeostasis, excitotoxicity, destruction of vascular integrity, OS, inflammation, apoptosis, autophagy, and activation of the NOS pathway [56-62].

The impact on stroke pertains to an abundance of ROS and RNS, as well as OS-induced cell death pathways. So, what role could OS have in depression? Depression involves several pathological processes that include an imbalance of neurotransmitters, inflammation, OS, apoptosis, glutamate excitotoxicity, and the microbiota-gut-brain axis [10,63-65]. Although there is a deficiency of direct evidence exhibiting mechanisms between OS and depression, numerous animal and human studies have reported functions of OS in depressed patients via various OS-associated molecules [66-69]. For example, Pasquali et al. conducted a longitudinal study and described a series cascade of pro-oxidative and pro-inflammatory events contributing to the development of MDD in middle-aged women [70]. Besides hyperactive OS, reduced antioxidant activity may exacerbate depression, but antioxidant treatment shows antidepressant effects [71-74]. Wigner et al. proved that the polymorphisms of antioxidant enzymes (e.g., superoxide dismutase (SOD) and catalase (CAT) or glutathione peroxidase $(\mathrm{GPx})$ ) could regulate the risk of depression [72]. Parallel results in the clinical trial were found to reach a consistency in the effects of OS in depression [75].

\subsection{Common oxidative stress-mediated process between stroke and depression}

In previous sections, it is mentioned that OS-mediated pathological mechanisms (e.g., inflammation and apoptosis) act as a bridge and exert functions in stroke and depression (Fig. 5). Details about common OS-induced mechanisms are shown as follows.

\subsubsection{Oxidative stress-mediated inflammation}

Overproduction of ROS and RNS can activate inflammatory processes to aggravate brain damage through glycogen synthase kinase 3 (GSK-3) and 
endothelial injury. ROS stimulate the phosphorylation of GSK-3 to negatively affect the cyclic adenosine monophosphate response element-binding protein (CREB) by suppressing its nuclear translocation, resulting in an increased expression of pro-inflammatory cytokines and brain dysfunction in ischemic rat [76, 77]. To be specific, activated GSK-3 downregulates Nrf2ARE binding activity and decreases the expression levels of genes downstream of Nrf2-ARE [78], but it stimulates the Toll-like receptors (TLRs) in the peripheral blood mononuclear cells [79]. Experiments indicate that TLR 4 induces the expression of inflammatory elements through activation and nuclear translocation of NF- $\mathrm{BB}$, while deletion of TLR 4 attenuates ischemic cerebral injury [80]. Additionally, GSK-3 could boost inflammation by interrupting CREB binding proteins, which are the coactivators of CREB and NF- $\mathrm{KB}$ in the nucleus $[76,81]$. Inversely, inhibition of GSK-3 $\beta$ improves the transcription and expression of anti-inflammatory cytokines and reduces pro-inflammatory cytokine production [79]. Therefore, the results of GSK-3 activation and GSK-3 suppression confirm the role of OSinduced inflammation in ischemic brain injury. In addition to GSK-3, oxidative injury of platelet and endothelium cells also participate in inflammation. Following endothelial impairment, P-selectin is highly expressed to induce the rolling of leukocytes on the endothelium, facilitating stable adhesion between leukocytes and endothelial cells [82, 83]. Afterwards, the adhered leukocytes release matrix metalloproteinase, break down the $\mathrm{BBB}$, and enter into the brain parenchyma to trigger a series of inflammatory processes [84]. In ICH, a similar process occurs [51]. In $\mathrm{SAH}$, free $\mathrm{Hb}$ stimulates endothelial cells to express cell adhesion molecules to attract neutrophils. Cells trapped in the subarachnoid space then undergo an oxidative burst, which releases ROS-mediated inflammatory cytokines or other molecules to further damage the brain [56].

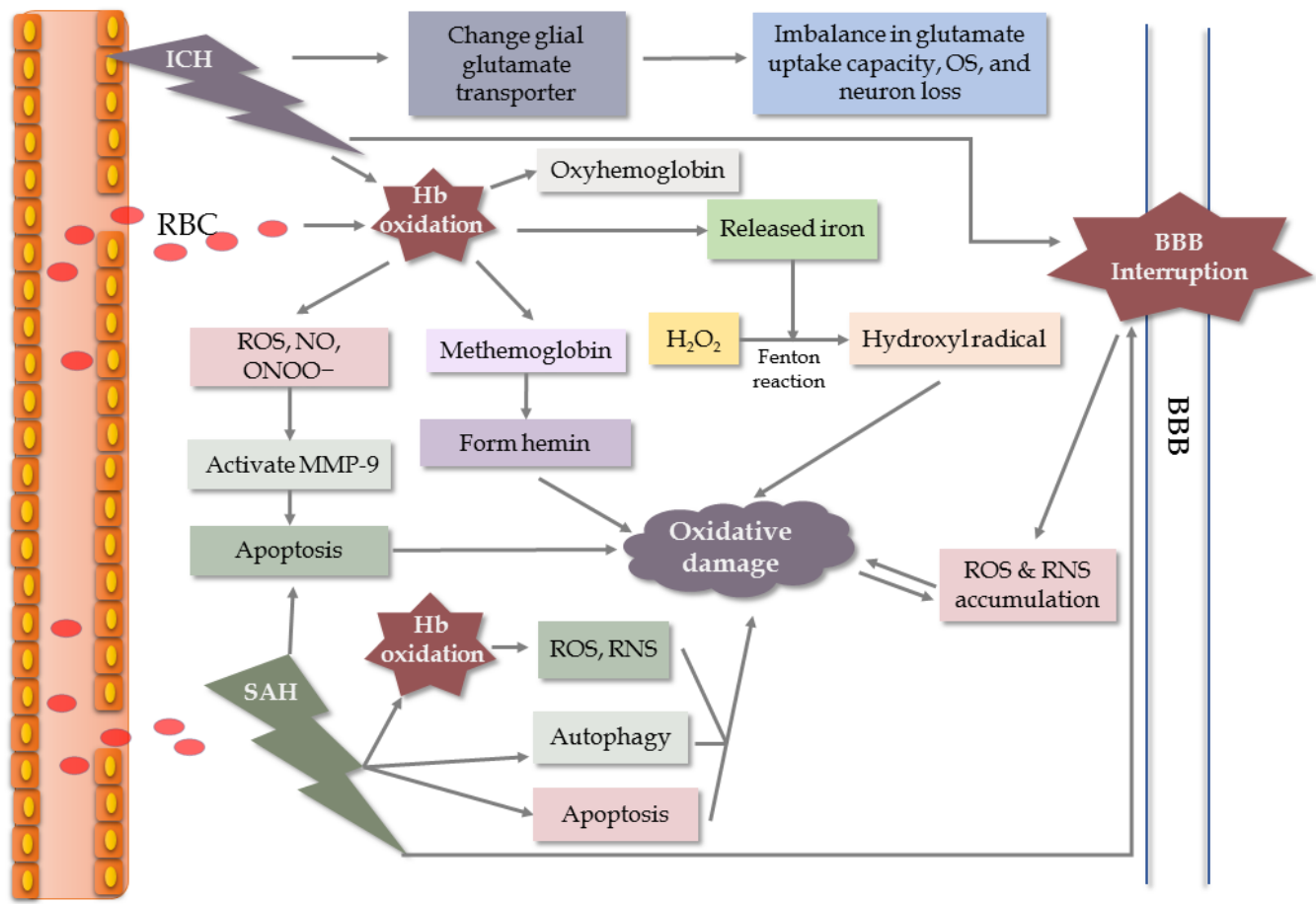

Figure 4. Schematic model of oxidative mechanisms in ICH and SAH, especially associated with hemoglobin (Hb). During the hemoglobin-heme-iron axis, $\mathrm{Hb}$ is released into the extracellular space and is accompanied by an abundance of superoxide generated from the non-enzymatic oxidation of $\mathrm{Hb}$ [46]. This oxidation of $\mathrm{Hb}$ produces methemoglobin, which releases heme to stimulate lipid peroxidation and other oxidative actions around the hematoma in brain tissue. Meanwhile, iron released from $\mathrm{Hb}$ degradation is used in the Fenton reaction to transform $\mathrm{H}_{2} \mathrm{O}_{2}$ into the hydroxyl radical, leading to increased oxidative damage [47].

In depressed individuals, ROS and RNS have effects on inflammatory reactions via NOD-, LRR- and pyrin domain-containing protein 3 (NLRP3)[85]. After sensing mitochondrial dysfunction of ROS, activated NLRP3 inflammasome induce the maturation of procaspase-1, which is an initiating process of interleukin (IL) $1 \beta$ and IL-
18 , to initiate inflammatory responses. Nevertheless, IL$1 \beta$ knock-down in the hippocampus attenuate depressionlike behaviors induced by LPS in mice [86]. However, these changes are reversed by treatment with amitriptyline $[87,88]$. In addition, pattern recognition receptors 
recognize PAMPs and DAMPs to trigger MAPK and/or

NF- $\kappa B$ to activate immune-inflammation $[89,90]$.

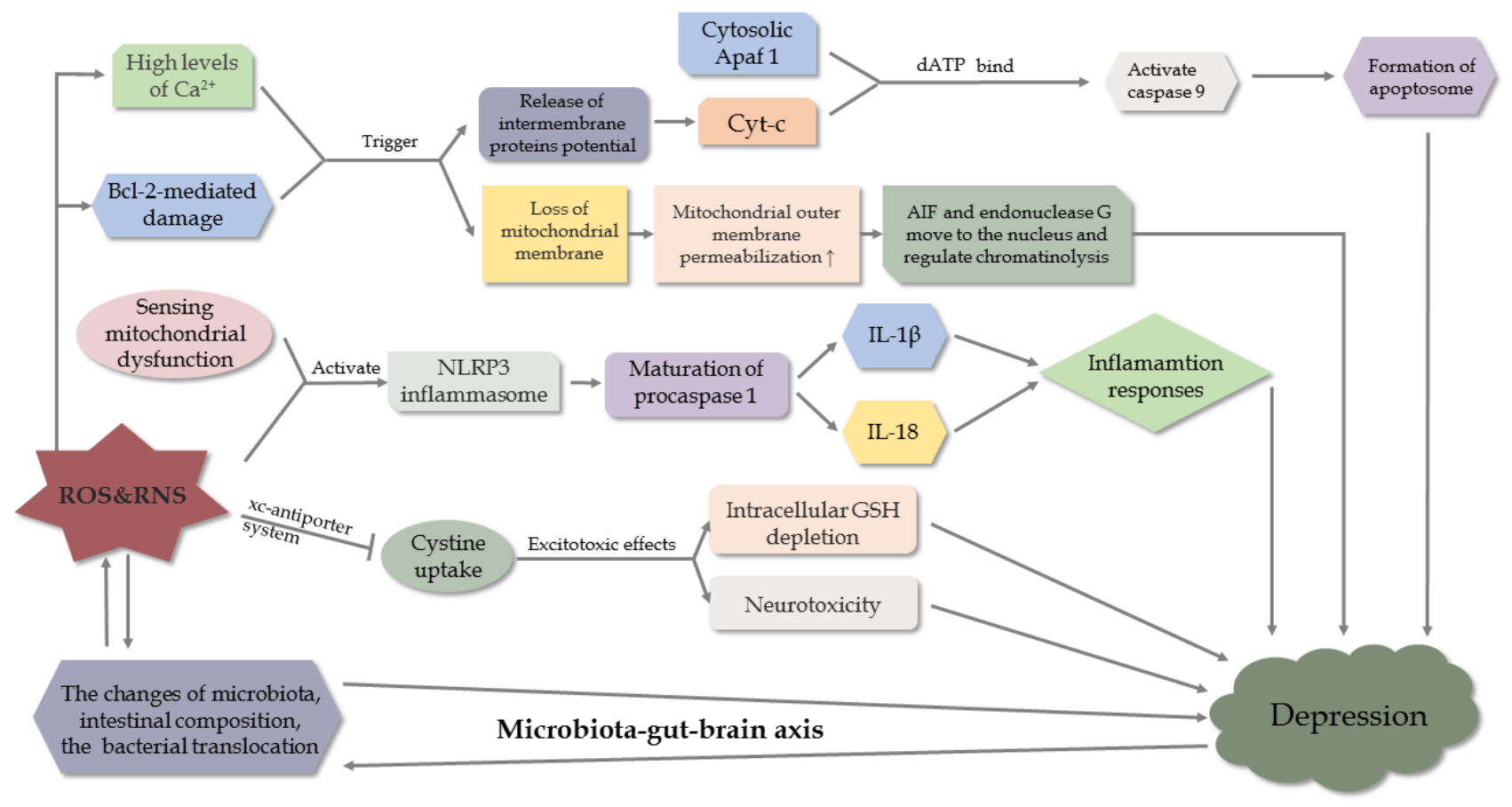

Figure 5. Mechanisms of oxidative stress and OS-mediated cell death pathway in depression.

\subsubsection{Oxidative stress-mediated apoptosis}

Accumulating evidence has shown that apoptosis, necrosis, and their combined pathway, "necroptosis", participated in ischemic stroke stimulated by ROS and RNS [91]. Experimental data obtained from ischemic mouse models suggest that the nuclei of neurons exhibit apoptotic morphology after four hours of ischemia [92]. Mechanistically, under pathological conditions, cellular stress stimulates an apoptotic signaling pathway to activate the caspase protease and cause mitochondrial dysfunction, resulting in characteristic changes of apoptotic cell morphology, such as cell rounding, plasma membrane blebbing, and nuclear fragmentation. Apoptosis can be induced by extrinsic and intrinsic stimuli. The extrinsic stimuli are triggered by the death receptor signaling pathway [93], while the intrinsic stimuli involve a mitochondrial signaling pathway and released cytochrome c (Cytc) [94]. When ischemic stroke occurs, OS initiates the apoptosis pathway mainly through intrinsic stimulation. OS also regulates apoptotic activities through modulating the balance between the anti-apoptotic protein, $\mathrm{Bcl}-2$, and the pro-apoptotic regulator, Bax protein [94]. In ICH, Cytc-mediated and mitochondria-dependent apoptosis is also demonstrated to be an important part of the OS-mediated mechanisms.
Additionally, Hb-induced ROS, NO, and peroxynitrite (ONOO-) are shown to directly or indirectly activate matrix metalloprotein 9, leading to apoptosis [95, 96]. Meanwhile, there is a significant increase in the number of apoptotic neural cells in the rat brain after SAH [60].

Parallel to OS-mediated apoptosis in stroke, intrinsic apoptosis associated with mitochondria occupies an important position in the development of depression. When exposed to chronic stress, overactive apoptosis stimulated by OS in neurons promotes the neurodegeneration in depressed animals [97]. Mechanistically, Bcl-2-mediated damage and excess levels of $\mathrm{Ca}^{2+}$ trigger various kinases, leading to a loss of the mitochondrial membrane potential, and an increased release of intermembrane proteins into the cytoplasm. In the presence of dATP, the released Cytc binds to the cytosolic Apaf 1 to activate caspase-9 and promote apoptosome formation. Meanwhile, enhanced permeability of the outer membrane of the mitochondria allows apoptosis-inducing factor (AIF) and endonuclease $\mathrm{G}$ to move to the nucleus and regulate chromatinolysis [97]. In addition, chronic mild stress suppresses the expression of Bcl-2-associated athanogene-1, a gene involved in anti-apoptosis, resulting in the activation of caspases, BAX, and $\mathrm{Bcl}-2$ antagonists in the mitochondria. Consequently, there is an excess of 
neuronal death [98]. Moreover, it is highlighted that polymorphisms of apoptotic protein genes may be associated with MDD [99].

\subsubsection{Oxidative stress-mediated microbiota-gut-brain axis}

Recently, the microbiota-gut-brain axis has gained extensive attention as a channel for communication and physiological regulation. Activities of the intestinal microbiome might promote abnormal protein aggregation and oxidative responses to impair the brain. Inversely, the brain can either directly or indirectly impact commensal organisms or gastrointestinal functions through the release of signaling molecules from cells in the lamina propria $[100,101]$. After an ischemic stroke, there is an increase of gastrointestinal complications such as dysphagia [102], fecal incontinence [103], gastrointestinal hemorrhage ${ }^{[104]}$, and constipation [105]. Wen et al. revealed that ischemic stroke exacerbates gut barrier breakdown and microbiota alterations. Subsequently, the translocation of a selective bacterial strain from the host intestinal microbiota to the surrounding tissues promotes post-stroke infections [106]. Furthermore, Benakis C et al. suggested that intestinal dysbiosis disequilibrates the intestinal immune homeostasis by inhibiting interleukin17-positive $\gamma \delta \mathrm{T}$ cells, and suppressing the trafficking of effector T cells from the gut to the leptomeninges [107]. Moreover, vagal afferent innervation of the enterochromaffin cells provides direct signaling to the neuronal circuits, leading to changes of the immuneresponse and other homeostatic functions [108]. Due to lack of data showing the relationship the among gut-brain axis and $\mathrm{ICH}$ or $\mathrm{SAH}$, further studies are needed.

In depression, the changes of microbiota, intestinal composition, and the resultant bacterial translocation expand the content of two-way interaction of the gut-brain axis. Zhang $\mathrm{P}$ et al. recognized the gut microbiome as an environmental factor that can shape the brain through this axis. Data from clinical sampling showed a significant difference of gut microbiota compositions between MDD patients and healthy controls, demonstrating that gut dysbiosis may mediate the host's metabolism to promote depressive-like behaviors [109]. In addition, gut dysbiosis could have an impact on the biology of MDD through several pathways involving immune activation, ROS and RNS, and neuroplasticity cascades [110]. Therefore, the microbiota-gut-brain axis may play a key role in the pathophysiological process of MDD. This axis opens a new preventative and therapeutic perspective for depression. However, due to methodological inconsistencies and limitations, more fundamental and clinical research should be undertaken.

\section{Roles of aging in stroke and depression via oxidatvie stress}

The preceding content shows us a close connection between stroke and depression via the OS system and OSmediated biological processes. Moreover, numerous studies have proved that aging or senescence is a risk factor that aggravates stroke and depression. For example, the population-based multiethnic cohort reported that the risk effect of physical inactivity is modified by age, and there is a conspicuous risk found only in stroke patients $>80$ years of age [111, 112]. Population-based surveillance studies predicted that the number of strokes will double by 2050 , with incidence occurring primarily in the elderly (>age 75) groups [113]. Although depression prevalence in the elderly varies across studies, Sjoberg L et al. indicated that older adults with poor physical function have a higher prevalence of depression [114]. Herein, there is an "aging-stroke-depression" network and OS seems to be the center of this network. So, what relationship does aging have with oxidative stress, stroke, and depression?

\subsection{Aging and oxidative stress}

There is a close link between oxidative stress and aging, and this link can be proven through many related mechanisms [115, 116]. Firstly, age-related cognitive decline is a consequence of increased OS and neuroinflammation activity in the the aging hippocampus, and a consequence of reduced neurogenesis and synaptic plasticity [117]. Furthermore, mutual effects of inflammation and OS are observed to exacerbate the aging brain. Inflammation stimulates both macrophages and microglia to generate mitoROS to cause cognitive decline, whereas OS-damaged cells produce inflammatory mediators to promote microglial aging [118]. Secondly, aging and OS can damage the brain by negatively affecting neuroplasticity, brain homeostasis, and cognitive function $[119,120]$. The third factor is glutathione. In animal experiments, glutathione deficiency might compromise the ability of the aging brain to meet the demands of OS, leading to impaired physiological functions [121].

\subsection{Aging and stroke}

Normally, physiological events of aging involve a decline of innate functions, including shortened telomeres, dysregulated hormones, and dampened immune responses. Under pathological conditions, aging stimulates and exacerbates cellular injuries, such as DNA damage and FR accumulation, to increase the vulnerability of the brain [122]. Mattson MP et al. 
depicted ten hallmarks of brain aging (e.g., OS and impaired DNA repair), among which, dysregulated energy metabolism is the core factor [122]. When exposed to ischemia, aging impairs the integrity of the neurovascular unit and damages brain tissues [123]. Aging can also destroy collateral circulation and revascularization of the brain through increased FR and inflammatory responses to aggravate stroke [124]. Agerelated cognitive deteriorations also exist in the $\mathrm{ICH}$ mice model. Researchers showed a delayed neurological improvement and decreased levels of antioxidants in senescence-accelerated mice than senescence-accelerated resistant mice, though the time period in which the neurological deficits occurred and increased remains the same. To conclude, these results implied a key role of OS in senescence and stroke.

Apart from OS, several other mechanisms are involved in OS and stroke. The ubiquitin proteasome pathway protects neurons by removing abnormal or toxic proteins located in the axons and dendrites, and ischemia may exacerbate injury of an aged brain through impairing ubiquitin proteasome function [125]. Furthermore, aging is detrimental to ischemic stroke recovery due to its role in altering astrocytic proliferation, inhibiting vascular endothelial growth factor (VEGF) production, and upregulating the release of inflammatory cytokines [126, 127]. What about aging in hemorrhagic stroke? Apart from the direct effects of aging in $\mathrm{ICH}$, senescence may contribute to ICH progression by changing the body physiology and increasing the risk of multiple chronic health conditions and comorbidities, such as hypertension and diabetes [128]. However, the exact mechanism remains unclear. To our knowledge, there is no clear evidence explaining a relation between SAH and aging.

\subsection{Aging and depression}

In the process of aging, biological changes in depression include mitochondrial dysfunction, dopamine dysfunction, and increased proinflammatory cytokines involved in the cellular senescence cycle. In general, mitochondrial abnormalities can be measured in peripheral blood mononuclear cells [129]. For instance, the clinical study by Karabatsiakis et al. depicted higher levels of mitochondrial impairments in older folks with depression when compared with healthy controls [130]. A systematic review and meta-analysis also supported this connection, indicating that late-life depression may be associated with a decreased hippocampal volume, though the relationship was not straightforward [131].

Different from other mechanisms in stroke, the pathological process of depression during aging is significantly affected by dopamine dysfunction, inflammation, and psychological stressors. In regards to dopamine, the availability of $\mathrm{D} 2$ receptors in the caudate and shell nuclei is attenuated in older adults, leading to decreased motor speed and impaired frontal functioning [132]. Worse still, dopamine levels in the striatum of the elderly are only $40 \%$ of those found in young adults, and the D1/D2 receptor density and dopamine transporter expression decreased approximately $10 \%$ per decade, throughout the life cycle [133, 134]. Secondly, studies have found that inflammatory processes, especially high expression levels of IL- 6 , TNF- $\alpha$, and C-reactive protein contribute to the depressive symptoms in elderly adults, with clinical manifestations of lethargy, slowing, and weakness [135]. Most importantly, psychological wellbeing is largely associated with the onset and progression of depression among the elderly population [136]. As the relationship between physical health and subjective wellbeing is bidirectional, elderly people with chronic diseases (e.g, coronary heart disease and chronic lung disease) have higher levels of unhappiness and are more likely to have depression [136]. Fourthly, a crosssectional survey showed that malnutrition increased the prevalence of depression in the elderly Nepali population. [137]. Lastly, low folate levels result in increased mild cognitive impairment, dementia, and depression in older individuals [138]. In summary, aging and depression are closely linked through OS, OS-related inflammation, and dopamine dysfunction, although social life and malnutrition play a crucial role in this link.

\subsection{Aging and oxidative stress in stroke or depression}

There are some changes of molecules and signaling pathways in aging. Under ischemia/hypoxia conditions among elderly individuals, silent information regulator 1 (SIRT1) expression and the mitochondrial unfolded protein response are reduced with age, leading to impairment of mitochondrial function [139]. This condition also occurs in another study, indicating that the post-translational regulation of molecular mediators, such as hypoxia-inducible factor $1 \alpha$ and SIRT1, and the glycolytic-mitochondrial energy axis are critical in response to hypoxic-ischemic injury [123]. Moreover, E2f transcription factor 1 enhances the cellular senescence in human fibroblast cells, while transcription factor FOXO3 plays against senescence by regulating ROS scavenging proteins. E2f transcription factor 1 could inhibit FOXO3-dependent transcription by directly binding to FOXO3 in the nucleus to expedite the aging process [140]. Interestingly, the telomerase reverse transcriptase (TERT), a catalytic subunit of telomerase, exerts neuroprotective effects in the mitochondria of neurons by decreasing the ROS and protecting DNA. Nevertheless, recent studies observe the neuroprotective effects of TERT in cellular and animal models after aged 
brain injury, but it is unclear about TERT's effects in the human CNS [141]. In regards to aging, OS, and depression, glutathione captures our attention. In a study enrolling 58 depressed older patients and 12 controls, glutathione was measured in the anterior cingulate cortex, and the data showed that increased glutathione/creatine ratios are associated with greater depressive symptoms than the control group [142]. In conclusion, OS lies in the center of the "aging-stroke-depression" network (Fig. 6). First, when stroke occurs in animals or patients, excessive generation of ROS follows, leading to cellular damage and brain injury. Second, OS mediates inflammation, apoptosis, and the microbiota-gut-brain axis to increase the accumulation of ROS, followed by brain deterioration. Third, aging acts as a risk factor and aggravates the development of stroke and depression via OS and OSinduced pathways. Due to the central role of OS in this network, administration of antioxidants seems to provide therapeutic ways for stroke and depression. So, are antioxidants safe and effective in these two disorders?

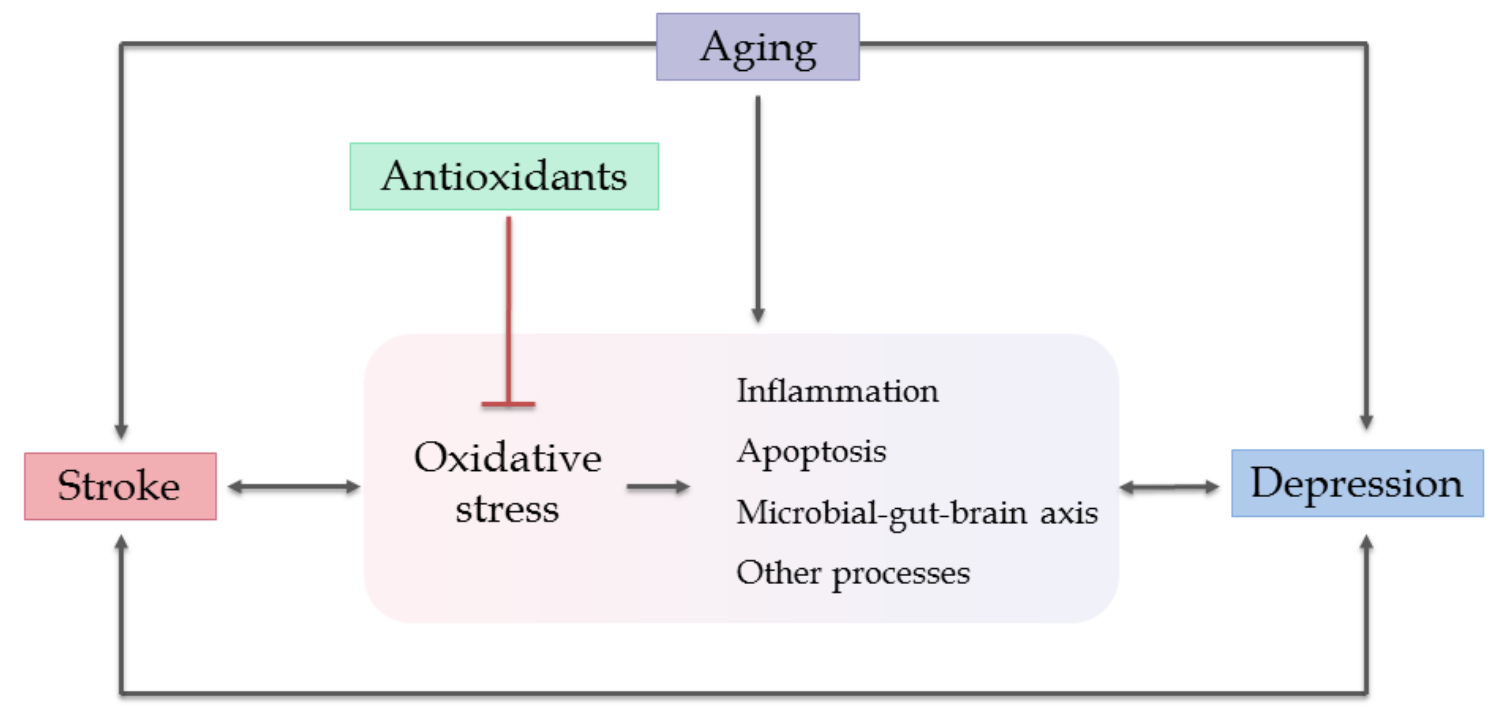

Figure 6. Proposed crosslink and interplay among aging, oxidative stress, stroke and depression.

\section{Antioxidants and antidepressants in stroke/ depression}

In the last 5 years, mountains of preclinical and clinical studies have found that the application of antioxidants inhibits stroke and depression in patients with either, or both diseases, although the therapeutic effects and safety are under consideration. What's more, the main pharmacotherapy for depression patients focuses on antidepressants [143], and the selective serotonin reuptake inhibitors (SSRIs) have been used as first-line antidepressants in recent decades. However, SSRIs have shown moderate efficacy and significant side-effects [10]. Variability in efficacy and acceptability are large in headto-head trials [144]. Therefore, development of an accurate and effective antidepressant regimen requires our constant efforts. Herein, we list most of the relative studies about antioxidants and antidepressants used in treating stroke/depression, in order to find potential therapies.

\subsection{Antioxidants in stroke}

Antioxidants or anti-oxidative systems have neuroprotective effects through different anti-activities and various signaling pathways, especially the Nrf2 pathway found in either ischemic stroke or hemorrhagic stroke (Table 1). Firstly, antioxidants alleviate ischemic stroke by attenuating the OS activity, and by protecting the mitochondrial function and BBB. For example, fucoxanthin [145], Sirtuin 6 [146], protocatechualdehyde [147], mangiferin [148], Korean Red Ginseng [149], 11Keto- $\beta$-boswellic acid [150], metformin [151], s-allyl cysteine [152], monomethyl fumarate[153], dieckol [154], and fumarate [155] are reported to protect the brain by activating the Nrf2/HO-1 pathway. As such, uric acid (UA) [156], HP-1c [157], andrographolide [158], 2,2,6,6tetramethyl-1-piperidinoxyl [159], and 3H-1,2-Dithiole3-thione are associated with Nrf2 [160]. Secondly, protecting mitochondrial function is beneficial to ischemic stroke treatment, such as 3-n-butylphthalide [161] and 5-methoxyindole-2-carboxylic acid [162].

Melatonin activates the silent information regulator 1 signaling [163], and progesterone suppresses mtROS production and blocks MPTP, to exert mitochondrial protection [164]. SkQR1 is a mitochondrial-targeted 
antioxidant, and it is effective in protecting newborn brains before and after ischemic stroke [165]. Thirdly, antioxidant systems also exert protective effects on blood vessels. For instance, ginkgolide [166] and leonurine [167] promote angiogenesis via upregulated VEGF expression. Fourthly, BBB integrity can be protected by several antioxidants, including astragaloside IV [168], Osthole [169] and the Chinese herbal medicine formula, Tao Hong Si Wu Decoction[170, 171]. All of these antioxidants are correlated with Nrf2 signaling.

Table 1 Antioxidants in Stroke.

\begin{tabular}{|c|c|c|c|}
\hline Stroke & Antioxidants & Anti-OS activity & Mechanism of anti-OS activity and others \\
\hline \multirow{36}{*}{$\begin{array}{l}\text { Ischemic } \\
\text { stroke }\end{array}$} & fucoxanthin & \multirow{16}{*}{ anti-OS } & \multirow{11}{*}{ inhibit OS via Nrf2/HO-1 signaling pathway } \\
\hline & Sirtuin 6 & & \\
\hline & protocatechualdehyde & & \\
\hline & mangiferin & & \\
\hline & Korean Red Ginseng & & \\
\hline & 11-Keto- $\beta$-boswellic acid & & \\
\hline & metformin & & \\
\hline & S-allyl cysteine & & \\
\hline & monomethyl fumarate & & \\
\hline & dieckol & & \\
\hline & fumarate & & \\
\hline & ursolic acid & & upregulate Nrf2 pathway and expression levels of BDNF \\
\hline & HP-1c & & $\begin{array}{l}\text { AMPK-Nrf2 pathway activation, without any toxicity after } \\
\text { penetrating the brain }\end{array}$ \\
\hline & andrographolide & & up-regulate Nrf2/HO-1 expression via regulation of p38 MAPK \\
\hline & $\begin{array}{l}\text { 2,2,6,6-tetramethyl-1- } \\
\text { piperidinoxyl }\end{array}$ & & inhibit p38 MAPK and p53 cascades \\
\hline & 3H-1,2-Dithiole-3-thione & & $\begin{array}{l}\text { suppress microglia activation; inhibit CNS peripheral cell } \\
\text { infiltration }\end{array}$ \\
\hline & 3-n-butylphthalide & & $\begin{array}{l}\text { inhibit OS; activate Nrf2/ HO-1 /AMPK pathway; improve MMP } \\
\text { and complexes I-IV }\end{array}$ \\
\hline & melatonin & anti-OS; attenuate & activate SIRT1 signaling \\
\hline & progesterone & mitochondrial & suppress mtROS production and block MPTP \\
\hline & $\begin{array}{l}\text { 5-methoxyindole-2-carboxylic } \\
\text { acid }\end{array}$ & dysfunction & $\begin{array}{l}\text { increase antioxidative capacity via the Nrf } 2 \text { signaling pathway; } \\
\text { reduce OS }\end{array}$ \\
\hline & SkQR1 & & protect mitochondria \\
\hline & GK & anti-OS; protect blood & $\begin{array}{l}\text { faciliate angiogenesis through } \mathrm{HIF}-1 \alpha / \mathrm{VEGF} \text { and JAK2/STAT3 } \\
\text { pathway }\end{array}$ \\
\hline & leonurine & & upregulate VEGF expression by Nrf-2 pathway \\
\hline & astragaloside IV & & Nrf2 signaling pathway \\
\hline & Tao Hong Si Wu Decoction & all-US, pIOtect DDD & anti-OS \\
\hline & schizandrin A & \multirow{11}{*}{$\begin{array}{l}\text { anti-OS; anti- } \\
\text { inflammation }\end{array}$} & AMPK/Nrf2 pathway \\
\hline & tryptanthrin & & $\begin{array}{l}\text { decrease pro-inflammatory cytokines in BV2 microglia cells via } \\
\text { Nrf2/ HO-1 signaling and NF- } \mathrm{BB}\end{array}$ \\
\hline & $\begin{array}{l}3,14,19 \text {-triacetyl } \\
\text { andrographolide }\end{array}$ & & inhibit TLR4/NF-кB; upregulate Nrf2/ARE \\
\hline & quercetin & & $\begin{array}{l}\text { suppress LPS-induced oxidant production and expression of } \\
\text { adhesion molecules }\end{array}$ \\
\hline & apelin 13 & & $\begin{array}{l}\text { affect AMPK/GSK-3 } \beta \text { pathway activated by } \\
\text { AR/G } \alpha / \mathrm{PLC} / \mathrm{IP} 3 / \mathrm{CaMKK} \text { signaling; }\end{array}$ \\
\hline & diosgenin & & suppress TLR4/MyD88/NF-kB-induced inflammation \\
\hline & irisin & & regulate ROS-NLRP3 inflammation \\
\hline & TPEN & & \multirow{3}{*}{ inhibit OS and inflammation } \\
\hline & $\begin{array}{l}\mathrm{N} \text {-acetyl lysyltyrosylcysteine } \\
\text { amide }\end{array}$ & & \\
\hline & Tanshinone IIA & & \\
\hline & berberine & & $\begin{array}{l}\text { reduce the infarct volume and brain edema; improve motor } \\
\text { function; }\end{array}$ \\
\hline
\end{tabular}




\begin{tabular}{|c|c|c|c|}
\hline & melilotus officinalis & & reduce cerebral thrombosis and inflammatory mediators \\
\hline & $\mathrm{DHC}$ & & $\begin{array}{l}\text { protect BBB; inhibit inflammation by affecting ROS, NOX2, } \\
\text { NOX } 4, \mathrm{NF}-\mathrm{KB} \text {, and NO }\end{array}$ \\
\hline & resveratrol & & $\begin{array}{l}\text { modulate intestinal flora-mediated Th17/Tregs and Th1/Th2 } \\
\text { polarity shift }\end{array}$ \\
\hline & EPO-cyclosporine & & $\begin{array}{l}\text { suppress the innate immune response to OS, inflammation and } \\
\text { MAPK family signaling }\end{array}$ \\
\hline & rhein & & \\
\hline & deuterohemin His peptide- 6 & & \\
\hline & acteoside & & inhibit OS and apoptosis \\
\hline & radix scrophulariae & & \\
\hline & pomalidomide & & \\
\hline & clostridium butyricum & & \\
\hline & adiponectin & anti-OS; anti-apoptosis & $\begin{array}{l}\text { attenuate mitochondrial vulnerability through the JAK2/STAT3 } \\
\text { pathway }\end{array}$ \\
\hline & YiQiFuMai & & reduce $\mathrm{PKC} \delta /$ Drp1-mediated mitochondrial fission \\
\hline & withania somnifera & & inhibit PARP1-AIF-Mediated caspase-independent apoptosis \\
\hline & SMXZF & & $\begin{array}{l}\text { suppress } \mathrm{H} 2 \mathrm{O} 2 \text {-induced neuronal apoptosis through caspase- } \\
\text { 3/ROCK1/MLC pathway }\end{array}$ \\
\hline & diallyl trisufide & & $\begin{array}{l}\text { suppress OGD-induced apoptosis via the PI3K/Akt-mediated } \\
\text { Nrf2/HO-1 signaling pathway }\end{array}$ \\
\hline & plumbagin & & \\
\hline & hollow prussian blue nanozymes & anti-OS; anti- & \\
\hline & geniposide & inflammation; anti- & inhibit OS, inflammation and apoptosis \\
\hline & curcumin & & \\
\hline & hexahydrocurcumin & & \\
\hline & Sirt3 & promote autonbagy & $\begin{array}{l}\text { regulate the AMPK-mTOR pathway; decrease } \mathrm{H} 2 \mathrm{O} 2 \text {; increase } \\
\text { ATP generation }\end{array}$ \\
\hline & $\beta$-arrestin-1 & promote autopnagy & $\begin{array}{l}\text { interact two major components of the BECN1 autophagic core } \\
\text { complex }\end{array}$ \\
\hline & vitexin & & inhibit autophagy through the mTOR/Ulk1 pathway \\
\hline & silibinin & & suppress the mitochondrial and autophagic cell death pathways \\
\hline & 3-methyladenine & anti-autophagy & inhibit expression of LC3 and Beclin-1 \\
\hline & astragalosides & & $\begin{array}{l}\text { block OGD-R-induced apoptosis and autophagy by inhibiting OS } \\
\text { and ER stress }\end{array}$ \\
\hline & isoquercetin & $\begin{array}{l}\text { anti-OS; anti- } \\
\text { inflammation; anti- }\end{array}$ & 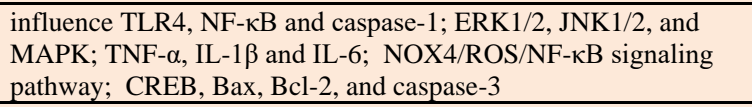 \\
\hline & ECGG & apoptosis; anti-autophagy & $\begin{array}{l}\text { affect PI3K/AKT/eNOS and NRF2/HO-1 signaling pathway; } \\
\text { promote neovascularization and cell proliferation }\end{array}$ \\
\hline & green tea & & \\
\hline & cofilin & & reduce EBI \\
\hline & $\begin{array}{l}\text { mammalian sterile } 20 \text {-like kinase- } \\
1\end{array}$ & & reduce EBI \\
\hline & melatonin & anti-OS & reduce DNA damage and MPTP opening \\
\hline & dexmedetomidine & & inhibit PGC- $1 \alpha$ pathway inactivation and mtROS \\
\hline & oleuropein & & alleviate brain edema; preserve the BBB \\
\hline & adiponectin & & alleviate brain edema; preserve the ВВВ \\
\hline & isoliquiritigenin & anti-OS; anti- & 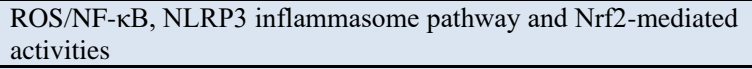 \\
\hline $\mathrm{ICH}$ & Sirt3 & & suppress NLRP3 and IL-1 $\beta$ levels \\
\hline & Sodium Benzoate & anti-OS; anti-apoptosis & $\begin{array}{l}\text { regulate DJ-1/Akt/IKK/NFkB pathway to inhibit neuronal } \\
\text { apoptosis and mtROS }\end{array}$ \\
\hline & carnosine & & decrease brain edema, BBB disruption, OS and neuronal apoptosis \\
\hline & metformin & & \\
\hline & baicalein & & inbibit $O S$ anontocic and nouroinflammation \\
\hline & hydrogen gas & anti-OS; anti- & 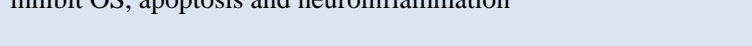 \\
\hline & protocatechuic acid & inflammation; anti- & \\
\hline & $\begin{array}{l}\text { hypoxia-inducible factor prolyl } \\
\text { hydroxylase domain (HIF-PHD) } \\
\text { metalloenzymes }\end{array}$ & & abolish ATF4-dependent neuronal death \\
\hline $\mathrm{SAH}$ & dimethyl formamide & anti-OS & $\begin{array}{l}\text { improve EBI and cognitive dysfunction via the Keap1-Nrf2-ARE } \\
\text { system }\end{array}$ \\
\hline & telmisartan & & decrease TXNIP expression \\
\hline
\end{tabular}




\begin{tabular}{|c|c|c|}
\hline nebivolol & \multirow{2}{*}{$\begin{array}{l}\text { anti-OS; inhibit cerebral } \\
\text { vasospasm }\end{array}$} & increase GSH-Px activity \\
\hline curcumin & & reduce TNF- $\alpha$ \\
\hline curcumin nanoparticles & \multirow{3}{*}{$\begin{array}{l}\text { anti-OS; anti- } \\
\text { inflammation }\end{array}$} & $\begin{array}{l}\text { keep BBB integrity; activate glutamate transporter-1; inhibit } \\
\text { inflammation and OS }\end{array}$ \\
\hline UA & & suppress the TLR4-mediated inflammatory pathway \\
\hline pterostilbene & & inhibit NLRP3 inflammasome and Nox2-related OS \\
\hline apigenin & \multirow{10}{*}{ anti-OS; anti-apoptosis } & \multirow{8}{*}{$\begin{array}{l}\text { inhibit EBI through the dual effects of anti-oxidation and anti- } \\
\text { apoptosis }\end{array}$} \\
\hline peroxiredoxin $1 / 2$ & & \\
\hline docosahexaenoic acid & & \\
\hline sodium hydrosulfide & & \\
\hline cysteamine & & \\
\hline gastrodin & & \\
\hline naringin & & \\
\hline progesterone & & \\
\hline AVE 0991 & & $\begin{array}{l}\text { decreases OS and neuronal apoptosis through Mas/PKA/p- } \\
\text { CREB/UCP-2 pathway }\end{array}$ \\
\hline allicin & & extenuate brain edema and BBB dysfunction; \\
\hline mangiferin & \multirow{4}{*}{$\begin{array}{l}\text { anti-OS; anti- } \\
\text { inflammation; } \\
\text { anti-apoptosis }\end{array}$} & regulate the mitochondrial apoptosis pathway, NLRP3 and NF- $\kappa$ B. \\
\hline memantine & & $\begin{array}{l}\text { inhibit inflammation-mediated BBB breakdown and ER stress- } \\
\text { based apoptosis }\end{array}$ \\
\hline Salvianolic acid B & & activate Nrf2 signaling pathway \\
\hline Salvianolic acid A & & $\begin{array}{l}\text { associate with Nrf2 signaling, the phosphorylation of ERK and } \\
\text { P38 MAPK signaling }\end{array}$ \\
\hline mitoquinone & promote autophagy & activate mitophagy via Keap1/Nrf2/PHB2 (prohibitin 2) pathway \\
\hline melatonin & promote autophagy & stimulate autophagy to inhibit apoptotic death of neural cells \\
\hline
\end{tabular}

Moreover, the anti-OS and anti-inflammatory effects are beneficial for post-ischemic treatment. Schizandrin A inhibits inflammation and OS through the AMPK/Nrf2 pathway [172]. Tryptanthrin [173], 3, 14, 19-triacetyl andrographolide [174], quercetin [175], diosgenin [176] and irisin [177] reduce the production of proinflammatory cytokines by inhibiting the NF- $\kappa$ Brelated signaling pathways and suppressing ROS generation. In addition, the Zinc ion chelating agents, TPEN [178], N-acetyl lysyltyrosylcysteine amide [179], Tanshinone IIA [180], resveratrol [181] and EPOcyclosporine combination therapy [182] preserve neuronal function through anti-OS and anti-inflammatory mechanisms of action. Furthermore, many antioxidants have effects on neuroprotection via anti-OS and antiapoptosis. Rhein [183], deuterohemin His peptide-6 [184], acteoside [185], Radix scrophulariae [186], pomalidomide [187], and Clostridium butyricum [188] protect the brain against cerebral $I / R$ injury by inhibiting apoptosis and OS. Similarly, adiponectin [189], YiQiFuMai [190], epigallocatechin-3-gallate (EGCG) [191] , Withania somnifera [192], SMXZF [193], and diallyl trisulfide [194] lessen neuronal impairment by attenuating mitochondrial caspase-independent apoptosis. Besides, plumbagin [187], hollow prussian blue nanozymes [195], geniposide [196], curcumin [197], and hexahydrocurcumin [198] play a role in neuronal protection by anti-OS, anti-inflammatory, and antiapoptotic activities. In addition, as autophagy is a doubleedged sword, promoting or inhibiting autophagy to exert neuroprotective effects depends on different conditions. On one hand, Sirt3 [199] and $\beta$-arrestin-1 [200] promote autophagy to play a neuroprotective role. On the other hand, vitexin [201], silibinin [202]. 3-methyladenine [203], and astragalosides [204] inhibit autophagy to protect the brain. It is also worth mentioning that isoquercetin [205, 206] and EGCG [207] alleviate brain impairment via anti-OS, anti-inflammatory, antiapoptotic, and anti-autophagocytic properties.

Like ischemic stroke, antioxidant defenses involving OS and OS-related processes are also found in ICH and SAH. Green tea [208, 209], cofilin [210], and mammalian sterile 20-like kinase-1 [211] play a major role in ICHinduced SBI. Melatonin [51] and dexmedetomidine [212] reduce mitochondrial impairments and ameliorate SBI. Analogously, oleuropein [213] and adiponectin [214] attenuate brain edema and preserve the BBB structure in a dose-dependent manner. In addition, isoliquiritigenin [215] and Sirt3 [216] improve ICH by inhibiting inflammatory and OS activities, whereas Sodium Benzoate [217] and carnosine [218] attenuate SBI and brain edema through suppression of neuronal apoptosis. As such, metformin [219], baicalein [220], hydrogen gas [221], protocatechuic acid [222], and hypoxia-inducible factor prolyl hydroxylase domain metalloenzymes [223] prevent neurological deficits after ICH by inhibiting apoptosis, OS, and neuroinflammation in rats. 
Table 2. Antioxidants in Depression.

\begin{tabular}{|c|c|c|c|}
\hline & Antioxidants & $\begin{array}{l}\text { Anti-OS } \\
\text { activity }\end{array}$ & $\begin{array}{c}\text { Mechanism of anti-OS activity and } \\
\text { others }\end{array}$ \\
\hline \multirow{26}{*}{ Depression } & bay $60-7550$ & \multirow{4}{*}{ anti-OS } & $\begin{array}{l}\text { downregulate gp91phox; activate the } \\
\text { cAMP/cGMP-pVASP-CREB-BDNF } \\
\text { signaling pathway }\end{array}$ \\
\hline & p-chloro-diphenyl diselenide & & modulate glutamate neurotransmission \\
\hline & homocysteine & & $\begin{array}{l}\text { inhibit ROS by activating NMDA } \\
\text { receptors }\end{array}$ \\
\hline & vitamin D & & suppress OS \\
\hline & $2,3,5,4$ '-tetrahydroxystilbene-2-O- $\beta$-D-glucopyranoside & \multirow{16}{*}{$\begin{array}{l}\text { anti-OS; anti- } \\
\text { inflammation }\end{array}$} & $\begin{array}{l}\text { reduce proinflammatory factors; restore } \\
\text { the diminished Akt signaling pathway; } \\
\text { faciliate astrocyte proliferation and } \\
\text { neurogenesis }\end{array}$ \\
\hline & vorinostat & & $\begin{array}{l}\text { modulate NF- } \mathrm{kB} \text { p65, COX-2 and } \\
\text { phosphorylated JNK levels }\end{array}$ \\
\hline & melatonin & & \multirow{13}{*}{ inhibit OS and inflammation } \\
\hline & naringenin & & \\
\hline & iptakalim & & \\
\hline & silymarin & & \\
\hline & resveratrol & & \\
\hline & honokiol & & \\
\hline & oxytocin & & \\
\hline & vanillin & & \\
\hline & trigonelline & & \\
\hline & quercetin & & \\
\hline & $\alpha$-tocopherol & & \\
\hline & baicalin & & \\
\hline & selenium-containing compounds & & \\
\hline & ketamine & & $\begin{array}{l}\text { increase glutamate release; affect } \\
\text { energy metabolism }\end{array}$ \\
\hline & mitochondrial uncoupling protein 2 & \multirow{6}{*}{$\begin{array}{l}\text { anti-OS; anti- } \\
\text { inflammation; } \\
\text { anti-apoptosis }\end{array}$} & $\begin{array}{l}\text { downregulate the activation of NLRP3 } \\
\text { inflammasome; suppress the ROS- } \\
\text { TXNIP-NLRP3 pathway in astrocytes }\end{array}$ \\
\hline & dl-3-n-butylphthalide & & \multirow{3}{*}{$\begin{array}{l}\text { inhibit OS, inflammatory responses and } \\
\text { apoptosis }\end{array}$} \\
\hline & indole-3-carbinol & & \\
\hline & 25-methoxyhispidol A & & \\
\hline & allicin & & $\begin{array}{l}\text { reduce neuroinflammation, OS, iron } \\
\text { overaccumulation; inhibit neuronal } \\
\text { apoptosis in the hippocampus }\end{array}$ \\
\hline & AVLE & & $\begin{array}{l}\text { suppress the apoptosis of hippocampus } \\
\text { cells via regulation of } \mathrm{Bcl}-2 / \mathrm{Bax} \\
\text { pathways }\end{array}$ \\
\hline
\end{tabular}

Many preclinical experiments in SAH have demonstrated that inhibiting OS and OS-mediated pathological processes alleviates alleviates EBI, SBI, and neuronal deficits. Dimethyl formamide improves cognitive dysfunction via the Keap1-Nrf2-ARE system [224]. Telmisartan [225], nebivolol [226] and curcumin [227] can ameliorate cerebral vasospasm, and Pterostilbene can attenuate EBI by inhibiting the NLRP3 inflammasome [228]. Some antioxidants (e.g., apigenin [229], peroxiredoxin1/2 [230], docosahexaenoic acid [231], sodium hydrosulfide [232], cysteamine [233], gastrodin [234], naringin [60], and progesterone [235]) play a neuroprotective role in EBI through the effects of anti-apoptosis after SAH, but other antioxidants (e.g. AVE 0991 and mangiferin [56, 236] memantine [59, 237], salvianolic acid B [238, 239], salvianolic acid A [240], and allicin [241]) protect against SAH-induced oxidative injury via inhibition of oxidative, inflammatory, and apoptotic pathways. Stimulating autophagy to inhibit apoptosis of neural cells also works in improving neurological outcome with administration of mitoquinone [242] and melatonin [243]. 
Table 3. Co-antioxidants in stroke and depression from experiments.

\begin{tabular}{|l|c|c|c|c|}
\hline \multicolumn{5}{|c}{ Co-antioxidants in stroke and depression from experiments } \\
\hline & \multicolumn{3}{c|}{ Stroke } & \multirow{2}{*}{ Depression } \\
\hline & Ischemic stroke & ICH & SAH & \\
\hline adiponectin & $\boldsymbol{V}$ & $\boldsymbol{V}$ & & \\
\hline ECGG & $\boldsymbol{V}$ & $\boldsymbol{V}$ & & \\
\hline metformin & $\boldsymbol{V}$ & $\boldsymbol{V}$ & & \\
\hline protocatechualdehyde & $\boldsymbol{V}$ & $\boldsymbol{V}$ & & \\
\hline Sirt3 & $\boldsymbol{V}$ & $\boldsymbol{V}$ & & \\
\hline curcumin & $\boldsymbol{V}$ & & $\boldsymbol{V}$ & \\
\hline DHC/A & $\boldsymbol{V}$ & & $\boldsymbol{V}$ & \\
\hline mangiferin & $\boldsymbol{V}$ & & $\boldsymbol{V}$ & \\
\hline progesterone & $\boldsymbol{V}$ & & & \\
\hline UA & $\boldsymbol{V}$ & & & $\boldsymbol{V}$ \\
\hline dl-3-n-Butylphthalide & $\boldsymbol{V}$ & & & $\boldsymbol{V}$ \\
\hline quercetin & & $\boldsymbol{V}$ & & $\boldsymbol{V}$ \\
\hline resveratrol & & & $\boldsymbol{V}$ & $\boldsymbol{V}$ \\
\hline baicalein & $\boldsymbol{V}$ & $\boldsymbol{V}$ & $\boldsymbol{V}$ & $\boldsymbol{V}$ \\
\hline allicin & & & & \\
\hline melatonin & & & & \\
\hline
\end{tabular}

\begin{tabular}{|l|l|l|l|l|}
\hline & \multicolumn{2}{|c|}{ Clinical trials and outcomes in stroke } & \multicolumn{2}{c|}{ Clinical trials and outcomes in depression } \\
\hline & \multicolumn{1}{|c|}{ Types } & \multicolumn{1}{c|}{ Outcomes } & \multicolumn{1}{c|}{ Types } & \multicolumn{1}{c|}{ Outcomes } \\
\hline flavonoid & meta-analysis & $\begin{array}{l}\text { high flavonoid reduces } \\
\text { risk of stroke }\end{array}$ & RCT & $\begin{array}{l}\text { higher flavonoid links to } \\
\text { lower depression risk } \\
\text { especially among women }\end{array}$ \\
\hline UA & RCT and \\
URICOICTUS & $\begin{array}{l}\text { UA is safe; UA } \\
\text { enhances outcomes of } \\
\text { stroke }\end{array}$ & $\begin{array}{l}\text { cohort studies } \\
\text { and meta- } \\
\text { analysis }\end{array}$ & $\begin{array}{l}\text { UA are associated with low } \\
\text { risk of depression } \\
\text { hospitalization and lower } \\
\text { MDA levels }\end{array}$ \\
\hline melatonin & RCT & $\begin{array}{l}\text { early melatonin usage } \\
\text { ameliorates the brain } \\
\text { injury of asphyxial } \\
\text { newborns }\end{array}$ & RCT & $\begin{array}{l}\text { buspirone-melatonin therapy } \\
\text { benefits cognitive function }\end{array}$ \\
\cline { 3 - 5 } & & $\begin{array}{l}\text { Reviatonin does not affect } \\
\text { mood disorders }\end{array}$ \\
\hline
\end{tabular}

\subsection{Antioxidants in depression}

Apart from stroke, using antioxidants may help improve depression. Generally, antioxidants exert antidepressant effects through their anti-OS characteristics (Table 2). Bay 60-7550 [244], p-chloro-diphenyl diselenide [245], homocysteine [246], and vitamin D [247] can attenuate depressive-like behaviors and improve depression. In a sense, the latest studies have focused on antioxidants that act against OS-induced inflammation. Examples of this include 2,3,5,4'-tetrahydroxystilbene-2-O- $\beta$-D- glucopyranoside [248] and vorinostat [249], which ameliorate inflammatory damage and OS to exert the antidepressant effect. Moreover, naringenin [250, 251], iptakalim [252], silymarin [253], resveratrol [254], honokiol [255], ketamine [256], melatonin [257], oxytocin [258], vanillin [259], trigonelline [260], quercetin [261], $\alpha$ tocopherol [262], baicalin [263] and selenium-containing compounds [264] have neuroprotective effects in the hippocampus of mice due to their antioxidant and antiinflammatory properties. Particularly, ketamine is involved in inducing the rapid antidepressant effects through increasing the release of glutamate in the body [265] and affecting energy metabolism in MDD [256]. Furthermore, some antioxidants with multifunctional properties demonstrate anti-OS, anti-inflammatory, and anti-apoptotic characteristics in depression. These antioxidants include mitochondrial uncoupling protein 2 [266], dl-3-n-butylphthalide [267], indole-3-carbinol [268], or 25-methoxyhispidol A [269] and allicin [270]. 
Of note, AVLE treatment has similar effects compared to fluoxetine on depression in the rat hippocampus [271].

\subsection{Co-antioxidants and promising drugs in stroke and depression}

Thus far, the use of antioxidants in animals has been successful in treating stroke or depression. According to the previous summarization, we have found some coantioxidants (Table 3). Additionally, several clinical trials show that co-antioxidants exert protections in stroke and depression, including flavonoid and melatonin.

\subsubsection{Flavonoids}

In stroke, high dietary flavonoid intake may modestly lower the risk of stroke due to its role in constraining OS-induced mitochondrial lipid peroxidation [272]. In depression, flavonoids can limit ROS production and promote the chelation of transition metal elements [273, 274]. Also, flavonoids act as reversible and competitive human monoamine oxidase inhibitors in the CNS, leading to increased central neurotransmission [275]. Moreover, a study enrolling 10,752 depressed individuals shows that higher flavonoid intake may be linked to lower depression risk, especially among older women [276].

\subsubsection{Uric Acid}

Table 4. Antidepressants in PSD treatment.
UA is the primary endogenous antioxidant in blood. A randomized, double-blind phase $2 \mathrm{~b} / 3$ trial (URICOICTUS) indicates that UA is safe without any concerns regarding safety, although the addition of UA to thrombolytic therapy does not raise the proportion of patients with excellent outcome after stroke [277]. However, a reanalysis of the URICOICTUS trial suggests that UA suppresses infarct growth, and is more effective than the placebo in reaching an excellent outcome in patients who are treated with alteplase following acute ischemic stroke [278]. Another clinical study supports the efficacy of UA therapy by showing decreased infarct growth and enhanced outcome in stroke survivors [279]. In depression, researchers have found that UA is associated with a low risk of hospitalization for depression after examining the plasma levels of UA in 96,989 depressed subjects [280]. Moreover, the efficacy of UA in depressed patients is supported by another largescale study [281].

\subsubsection{Melatonin}

To our knowledge, few clinical trials have studied the neuroprotective effects of melatonin on cerebral ischemia prevention. A prospective trial involving 45 neonates indicates that it is practicable to provide early administration of melatonin to ameliorate brain injury in a choking newborn infant [282]. In regards to treatment of MDD, preliminary findings of a study reveal that a combination of buspirone with melatonin can partially benefit cognitive function [283].

\begin{tabular}{|c|c|c|}
\hline $\begin{array}{l}\text { Antioxidants in } \\
\text { PSD }\end{array}$ & Clinical trials & Outcomes \\
\hline fluoxetine & FOCUS & $\begin{array}{l}\text { not support routine use of fluoxetine in preventing PSD or promoting } \\
\text { function recovery }\end{array}$ \\
\hline \multirow{2}{*}{ fluoxetine/paroxetine } & meta-analysis of 12 trials & $\begin{array}{l}\text { fluoxetine is the worst choice for PSD treatment; paroxetine is the best } \\
\text { drug in terms of efficacy and acceptability }\end{array}$ \\
\hline & meta-analysis of $20 \mathrm{RCTs}$ & $\begin{array}{l}\text { citalopram has similar efficacy and safety as other SSRIs but acts faster } \\
\text { than them }\end{array}$ \\
\hline fluoxetine & FLAME & exhibit a positive connection between motor recovery \\
\hline escitalopram & Cochrane review & $\begin{array}{l}\text { escitalopram is the best tolerated SSRI, followed by sertraline and } \\
\text { paroxetine for PSD }\end{array}$ \\
\hline escitalopram & $\mathrm{RCT}$ & $\begin{array}{l}\text { not take effects on depressive symptoms; diarrhea is more likely to } \\
\text { occur }\end{array}$ \\
\hline escitalopram & $\mathrm{RCT}$ & $\begin{array}{l}\text { effective at decreasing the incidence of depression in nondepressed } \\
\text { patients }\end{array}$ \\
\hline Citalopram & RCT & safe for patients with acute ischemic stroke \\
\hline Citalopram & RCT & different effects in different stages of PSD \\
\hline citalopram & RCT & SSRI treatment is well tolerated and beneficial in PSD \\
\hline SSRI & $\begin{array}{l}\text { registry-based score- } \\
\text { matched follow-up study }\end{array}$ & $\begin{array}{l}\text { pre-stroke SSRI use increases risk of the hemorrhagic stroke; no } \\
\text { increased stroke severity and mortality ischemic stroke }\end{array}$ \\
\hline milnacipran & $\mathrm{RCT}$ & $\begin{array}{l}\text { milnacipran prevents post-stroke depression; safe to use without serious } \\
\text { adverse events }\end{array}$ \\
\hline
\end{tabular}


Although many co-antioxidants are found in animal models of both diseases, only a few clinical trials have confirmed the efficacy of antioxidants in stroke and depression. The difficulty of antioxidants acting through the BBB in patients may be the reason for this result. Nevertheless, OS and OS-mediated pathways are comechanisms of stroke and depression. So, what is the role of antidepressants in stroke survivors?

\subsection{Antidepressants in post-stroke}

At present, antidepressant drugs are widely used for treating post-stroke depression (PSD), but there are many adverse reactions at the same time. These events include gastroenterological symptoms, falls/fracture, and epilepsy [284]. Therefore, future clinical trials should emphasize their focus on the efficacy and safety of antidepressant drugs in preventing or treating stroke (Table 4). Herein, we summarize some clinical trials in recent years with the objective of determining whether antidepressants (e.g., fluoxetine, escitalopram, milnacipran) are necessary for PSD patients. Results of FOCUS (effects of fluoxetine on functional outcomes after acute stroke) represent a lower incidence of new depression and a higher risk of bone fractures in the group in which fluoxetine is allocated, when compared with the controls. Those outcomes do not support the routine use of fluoxetine in preventing PSD or promoting function recovery [285]. In addition, a metaanalysis of 12 suitable trials demonstrated that fluoxetine is the worst choice for PSD treatment, while paroxetine is an effective and acceptable drug [286]. However, FLAME (fluoxetine for motor recovery after acute ischemic stroke) exhibits a positive connection between motor recovery and fluoxetine use in PSD patients [287]. The second drug is escitalopram. Kim K et al. did a Cochrane systematic review of 13 trials of antidepressant drugs, and confirmed that escitalopram is the most tolerated SSRI [288]. Another study also indicates that escitalopram was well-tolerated, though it does not have any effects on the depressive symptoms in PSD patients [289]. Robinson et al. illustrated that escitalopram is significantly effective at decreasing the incidence of depression in patients with recent stroke over 12-month therapy [290]. Thirdly, citalopram is reported to be a safe medication in patients with acute ischemic stroke [291], and it improves PSD [292]. In conclusion, fluoxetine is not necessary for PSD treatment, but it is good for motor recovery. Escitalopram and citalopram are both tolerated and may have benefits in PSD patients. However, the question of whether to allocate antidepressants in post-stroke patients is still controversial, when considering efficacy and safety. Additionally, is pre-stroke SSRI therapy useful for patients with stroke? Mortensen et al. conducted a study enrolling hemorrhagic stroke patients and ischemic stroke patients. They found that pre-stroke SSRI use increased severity and mortality in patients with hemorrhagic stroke, but there was no increase in ischemic stroke patients [293]. Finally, milnacipran also plays a role in preventing PSD and it is safe to use, without any serious adverse events, according to an RCT performed by ChingShu Tsai [294]. Due to the limited data showing a relationship between depressants and PSD, more multicenter clinical trials should be conducted.

\section{DISCUSSION}

This review discusses the central role of OS in the "agingstroke-depression" network and antioxidants in treating stroke or depression, as well as antidepressant in PSD. Although all of the studies have immeasurable contributions to scientific exploration, there are some limitations in the current studies. First, depression is a psychiatric disorder lacking effective biomarkers or methods, and depressive symptoms may be less apparent, making it difficult to procure an accurate diagnosis for depression [10]. Relatively uniform and accurate diagnostic criteria for depression must be improved [295]. Second, this review focuses on major depression, leaving an unclear relationship between other depression phases and stroke. Third, although this review suggests aging as a risk for stroke and depression, the link is often found in aged adults, but not analyzed in other age groups [296, ]33]. For future studies, it is suggested that there should be an emphasis on certain age demographics. Fourth, human brains have a natural and complex protective barrier, which prevents antioxidant drugs from entering into the CNS, partially explaining the reduced efficacy of these drugs in experimental models [297]. Finding carriers that can penetrate the blood-brain barrier, such as nanoparticles, may address this problem. Fifth, there are data deviations due to the lack of dose-response analysis, limitations on sample size, representativeness of the sample, statistical methods, inclusion criteria, and followup [37, 298, 299]. Therefore, studies should be conducted in a more precise manner. Furthermore, drug dose, window time, and methods of administration also warrant our attention. All things considered, further studies are required to improve the diagnosis of depression, to find drugs directed at overproduced ROS with higher efficacy and safety, and to enhance the quality of life after diseases.

\section{Acknowledgments}

This work was funded by the China Postdoctoral Science Foundation (2017M612010), National Natural Science Foundation of China (81701144, 81371433, and 8187 0916), and Major Science and Technology project in 
medical and health of Zhejiang Province (WKJ-ZJ1615:2016149634). Wish the global epidemic of 2019 novel coronavirus pneumonia ends soon.

\section{Conflict of interest}

The authors state that there was no conflict of interest in the preparation of this review.

\section{References}

[1] Newgard CB, Sharpless NE (2013). Coming of age: molecular drivers of aging and therapeutic opportunities. J Clin Invest, 123:946-950.

[2] Roy-O'Reilly M, McCullough LD (2018). Age and Sex Are Critical Factors in Ischemic Stroke Pathology. Endocrinology, 159:3120-3131.

[3] Schaakxs R, Comijs HC, Lamers F, Kok RM, Beekman ATF, Penninx B (2018). Associations between age and the course of major depressive disorder: a 2-year longitudinal cohort study. Lancet Psychiatry, 5:581-590.

[4] Benjamin EJ, Muntner P, Alonso A, Bittencourt MS, Callaway CW, Carson AP, et al. (2019). Heart Disease and Stroke Statistics-2019 Update: A Report From the American Heart Association. Circulation, 139:e56e528.

[5] DALYs GBD, Collaborators H (2018). Global, regional, and national disability-adjusted life-years (DALYs) for 359 diseases and injuries and healthy life expectancy (HALE) for 195 countries and territories, 1990-2017: a systematic analysis for the Global Burden of Disease Study 2017. Lancet, 392:18591922.

[6] Collaborators GBDCoD (2018). Global, regional, and national age-sex-specific mortality for 282 causes of death in 195 countries and territories, 1980-2017: a systematic analysis for the Global Burden of Disease Study 2017. Lancet, 392:1736-1788.

[7] Disease GBD, Injury I, Prevalence C (2017). Global, regional, and national incidence, prevalence, and years lived with disability for 328 diseases and injuries for 195 countries, 1990-2016: a systematic analysis for the Global Burden of Disease Study 2016. Lancet, 390:1211-1259.

[8] Kessler RC, Bromet EJ (2013). The epidemiology of depression across cultures. Annu Rev Public Health, 34:119-138.

[9] Bromet E, Andrade LH, Hwang I, Sampson NA, Alonso J, de Girolamo G, et al. (2011). Cross-national epidemiology of DSM-IV major depressive episode. BMC Med, 9:90.

[10] Malhi GS, Mann JJ (2018). Depression. Lancet, 392:2299-2312.

[11] Herrman H, Kieling C, McGorry P, Horton R, Sargent J, Patel V (2019). Reducing the global burden of depression: a Lancet-World Psychiatric Association Commission. Lancet, 393:e42-e43.
Ago T, Kuroda J, Pain J, Fu C, Li H, Sadoshima J (2010). Upregulation of Nox4 by hypertrophic stimuli promotes apoptosis and mitochondrial dysfunction in cardiac myocytes. Circ Res, 106:1253-1264.

Bedard K, Krause KH (2007). The NOX family of ROS-generating NADPH oxidases: physiology and pathophysiology. Physiol Rev, 87:245-313.

Sivandzade F, Bhalerao A, Cucullo L (2019). Cerebrovascular and Neurological Disorders: Protective Role of NRF2. Int J Mol Sci, 20.

Moylan S, Berk M, Dean OM, Samuni Y, Williams LJ, O'Neil A, et al. (2014). Oxidative \& nitrosative stress in depression: why so much stress? Neurosci Biobehav Rev, 45:46-62.

[16] Jiang X, Andjelkovic AV, Zhu L, Yang T, Bennett MVL, Chen J, et al. (2018). Blood-brain barrier dysfunction and recovery after ischemic stroke. Prog Neurobiol, 163-164:144-171.

[17] Xi G, Keep RF, Hoff JT (2006). Mechanisms of brain injury after intracerebral haemorrhage. Lancet Neurol, 5:53-63.

[18] Zolnourian A, Galea I, Bulters D (2019). Neuroprotective Role of the Nrf2 Pathway in Subarachnoid Haemorrhage and Its Therapeutic Potential. Oxid Med Cell Longev, 2019:6218239.

[19] Zuo G, Zhang T, Huang L, Araujo C, Peng J, Travis Z, et al. (2019). Activation of TGR5 with INT-777 attenuates oxidative stress and neuronal apoptosis via cAMP/PKCepsilon/ALDH2 pathway after subarachnoid hemorrhage in rats. Free Radic Biol Med, 143:441-453.

[20] Song Y, Cao W, Zhu X, Qiu Z, Yang X, Liu J, et al. (2017). F10, a novel hydatidiform mole-associated gene, inhibits the paclitaxel sensitivity of A549 lung cancer cells by downregulating BAX and caspase-3. Oncol Lett, 13:2563-2568.

[21] Keller J, Gomez R, Williams G, Lembke A, Lazzeroni L, Murphy GM, Jr., et al. (2017). HPA axis in major depression: cortisol, clinical symptomatology and genetic variation predict cognition. Mol Psychiatry, 22:527-536.

[22] Setiawan E, Wilson AA, Mizrahi R, Rusjan PM, Miler L, Rajkowska G, et al. (2015). Role of translocator protein density, a marker of neuroinflammation, in the brain during major depressive episodes. JAMA Psychiatry, 72:268-275.

[23] Schmaal L, Hibar DP, Samann PG, Hall GB, Baune BT, Jahanshad N, et al. (2017). Cortical abnormalities in adults and adolescents with major depression based on brain scans from 20 cohorts worldwide in the ENIGMA Major Depressive Disorder Working Group. Mol Psychiatry, 22:900-909.

[24] Boldrini M, Fulmore CA, Tartt AN, Simeon LR, Pavlova I, Poposka V, et al. (2018). Human Hippocampal Neurogenesis Persists throughout Aging. Cell Stem Cell, 22:589-599 e585.

[25] Black CN, Bot M, Scheffer PG, Cuijpers P, Penninx BW (2015). Is depression associated with increased oxidative stress? A systematic review and metaanalysis. Psychoneuroendocrinology, 51:164-175. 
[26] Black CN, Bot M, Scheffer PG, Penninx BWJH (2017). Oxidative stress in major depressive and anxiety disorders, and the association with antidepressant use; results from a large adult cohort. Psychological Medicine, 47:936-948.

[27] Lindqvist D, Dhabhar FS, James SJ, Hough CM, Jain FA, Bersani FS, et al. (2017). Oxidative stress, inflammation and treatment response in major depression. Psychoneuroendocrinology, 76:197-205.

[28] Bigornia SJ, Harris WS, Falcon LM, Ordovas JM, Lai CQ, Tucker KL (2016). The Omega-3 Index Is Inversely Associated with Depressive Symptoms among Individuals with Elevated Oxidative Stress Biomarkers. Journal of Nutrition, 146:758-766.

[29] Tsuboi H, Sakakibara H, Tatsumi A, YamakawaKobayashi K, Matsunaga M, Kaneko H, et al. (2019). Serum IL-6 levels and oxidation rate of LDL cholesterol were related to depressive symptoms independent of omega-3 fatty acids among female hospital and nursing home workers in Japan. J Affect Disord, 249:385-393.

[30] Limampai P, Wongsrithep W, Kuptniratsaikul V (2017). Depression after stroke at 12-month follow-up: a multicenter study. International Journal of Neuroscience, 127:887-892.

[31] Shi Y, Xiang Y, Yang Y, Zhang N, Wang S, Ungvari GS, et al. (2015). Depression after minor stroke: Prevalence and predictors. J Psychosom Res, 79:143147.

[32] Maaijwee NA, Tendolkar I, Rutten-Jacobs LC, Arntz RM, Schaapsmeerders P, Dorresteijn LD, et al. (2016). Long-term depressive symptoms and anxiety after transient ischaemic attack or ischaemic stroke in young adults. Eur J Neurol, 23:1262-1268.

[33] Koivunen RJ, Harno H, Tatlisumak T, Putaala J (2015). Depression, anxiety, and cognitive functioning after intracerebral hemorrhage. Acta Neurol Scand, 132:179-184.

[34] Ackermark PY, Schepers VP, Post MW, Rinkel GJ, Passier PE, Visser-Meily JM (2017). Longitudinal course of depressive symptoms and anxiety after aneurysmal subarachnoid hemorrhage. Eur J Phys Rehabil Med, 53:98-104.

[35] Jackson CA, Mishra GD (2013). Depression and risk of stroke in midaged women: a prospective longitudinal study. Stroke, 44:1555-1560.

[36] Pan A, Sun Q, Okereke OI, Rexrode KM, Hu FB (2011). Depression and risk of stroke morbidity and mortality: a meta-analysis and systematic review. JAMA, 306:1241-1249.

[37] Booth J, Connelly L, Lawrence M, Chalmers C, Joice $\mathrm{S}$, Becker C, et al. (2015). Evidence of perceived psychosocial stress as a risk factor for stroke in adults: a meta-analysis. Bmc Neurology, 15.

[38] Wang YZ, Wang JJ, Huang Y, Liu F, Zeng WZ, Li Y, et al. (2015). Tissue acidosis induces neuronal necroptosis via ASIC1a channel independent of its ionic conduction. Elife, 4.

[39] Anwar MA, Eid AH (2016). Determination of Vascular Reactivity of Middle Cerebral Arteries from
Stroke and Spinal Cord Injury Animal Models Using Pressure Myography. Methods Mol Biol, 1462:611624.

[40] Lien LM, Chiou HY, Yeh HL, Chiu SY, Jeng JS, Lin HJ, et al. (2017). Significant Association Between Low Mitochondrial DNA Content in Peripheral Blood Leukocytes and Ischemic Stroke. Journal of the American Heart Association, 6.

[41] Zitnanova I, Siarnik P, Kollar B, Chomova M, Pazderova P, Andrezalova L, et al. (2016). Oxidative Stress Markers and Their Dynamic Changes in Patients after Acute Ischemic Stroke. Oxidative Medicine and Cellular Longevity.

[42] Liu Z, Liu Y, Tu X, Shen H, Qiu H, Chen H, et al. (2017). High Serum Levels of Malondialdehyde and 8-OHdG are both Associated with Early Cognitive Impairment in Patients with Acute Ischaemic Stroke. Sci Rep, 7:9493.

[43] Wang AX, Cui Y, Meng X, Su ZP, Cao YB, Yang YL, et al. (2018). The relationship between oxidized lowdensity lipoprotein and the NIHSS score among patients with acute ischemic stroke: The SOS-Stroke Study. Atherosclerosis, 270:21-25.

[44] Wang A, Liu J, Meng X, Li J, Wang H, Wang Y, et al. (2018). Association between oxidized low-density lipoprotein and cognitive impairment in patients with ischemic stroke. European Journal of Neurology, 25:185-191.

[45] Wang A, Yang Y, Su Z, Yue W, Hao H, Ren L, et al. (2017). Association of Oxidized Low-Density Lipoprotein With Prognosis of Stroke and Stroke Subtypes. Stroke, 48:91-97.

[46] Huang FP, Xi G, Keep RF, Hua Y, Nemoianu A, Hoff JT (2002). Brain edema after experimental intracerebral hemorrhage: role of hemoglobin degradation products. J Neurosurg, 96:287-293.

[47] Chen Q, Tang J, Tan L, Guo J, Tao Y, Li L, et al. (2015). Intracerebral Hematoma Contributes to Hydrocephalus After Intraventricular Hemorrhage via Aggravating Iron Accumulation. Stroke, 46:29022908.

[48] Wu H, Wu T, Li M, Wang J (2012). Efficacy of the lipid-soluble iron chelator 2,2'-dipyridyl against hemorrhagic brain injury. Neurobiol Dis, 45:388-394.

[49] Neves JD, Vizuete AF, Nicola F, Da Re C, Rodrigues AF, Schmitz F, et al. (2018). Glial glutamate transporters expression, glutamate uptake, and oxidative stress in an experimental rat model of intracerebral hemorrhage. Neurochem Int, 116:13-21.

[50] Katsu M, Niizuma K, Yoshioka H, Okami N, Sakata H, Chan PH (2010). Hemoglobin-induced oxidative stress contributes to matrix metalloproteinase activation and blood-brain barrier dysfunction in vivo. J Cereb Blood Flow Metab, 30:1939-1950.

[51] Wang Z, Zhou F, Dou Y, Tian X, Liu C, Li H, et al. (2018). Melatonin Alleviates Intracerebral Hemorrhage-Induced Secondary Brain Injury in Rats via Suppressing Apoptosis, Inflammation, Oxidative Stress, DNA Damage, and Mitochondria Injury. Transl Stroke Res, 9:74-91. 
[52] Meng C, Zhang J, Dang B, Li H, Shen H, Li X, et al. (2018). PERK Pathway Activation Promotes Intracerebral Hemorrhage Induced Secondary Brain Injury by Inducing Neuronal Apoptosis Both in Vivo and in Vitro. Front Neurosci, 12:111.

[53] Zhang Z, Song Y, Zhang Z, Li D, Zhu H, Liang R, et al. (2017). Distinct role of heme oxygenase-1 in earlyand late-stage intracerebral hemorrhage in 12-monthold mice. J Cereb Blood Flow Metab, 37:25-38.

[54] Zetterling M, Hallberg L, Ronne-Engstrom E (2010). Early global brain oedema in relation to clinical admission parameters and outcome in patients with aneurysmal subarachnoid haemorrhage. Acta Neurochir (Wien), 152:1527-1533; discussion 1533.

[55] Vergouwen MD, Vermeulen M, van Gijn J, Rinkel GJ, Wijdicks EF, Muizelaar JP, et al. (2010). Definition of delayed cerebral ischemia after aneurysmal subarachnoid hemorrhage as an outcome event in clinical trials and observational studies: proposal of a multidisciplinary research group. Stroke, 41:23912395.

[56] Zhang HM, Sang XG, Wang YZ, Cui C, Zhang L, Ji WS (2017). Role of Delta133p53 isoform in NFkappaB inhibitor PDTC-mediated growth inhibition of MKN45 gastric cancer cells. World J Gastroenterol, 23:2716-2722.

[57] Zhong JT, Yu J, Wang HJ, Shi Y, Zhao TS, He BX, et al. (2017). Effects of endoplasmic reticulum stress on the autophagy, apoptosis, and chemotherapy resistance of human breast cancer cells by regulating the $\mathrm{PI} 3 \mathrm{~K} / \mathrm{AKT} / \mathrm{mTOR}$ signaling pathway. Tumour Biol, 39:1010428317697562.

[58] Shi X, Fu Y, Zhang S, Ding H, Chen J (2017). Baicalin Attenuates Subarachnoid Hemorrhagic Brain Injury by Modulating Blood-Brain Barrier Disruption, Inflammation, and Oxidative Damage in Mice. Oxid Med Cell Longev, 2017:1401790.

[59] Fan LF, He PY, Peng YC, Du QH, Ma YJ, Jin JX, et al. (2017). Mdivi-1 ameliorates early brain injury after subarachnoid hemorrhage via the suppression of inflammation-related blood-brain barrier disruption and endoplasmic reticulum stress-based apoptosis. Free Radic Biol Med, 112:336-349.

[60] Han Y, Su J, Liu X, Zhao Y, Wang C, Li X (2017). Naringin alleviates early brain injury after experimental subarachnoid hemorrhage by reducing oxidative stress and inhibiting apoptosis. Brain Res Bull, 133:42-50.

[61] Dou Y, Shen H, Feng D, Li H, Tian X, Zhang J, et al. (2017). Tumor necrosis factor receptor-associated factor 6 participates in early brain injury after subarachnoid hemorrhage in rats through inhibiting autophagy and promoting oxidative stress. J Neurochem, 142:478-492.

[62] Wu H, Niu H, Wu C, Li Y, Wang K, Zhang J, et al. (2016). The autophagy-lysosomal system in subarachnoid haemorrhage. J Cell Mol Med, 20:17701778 .

[63] Barnes J, MondeIli V, Pariante CM (2017). Genetic Contributions of Inflammation to Depression.
Neuropsychopharmacology, 42:81-98.

[64] Amidfar M, Kim YK, Scaini G, Quevedo J (2018). Evidence for additionally increased apoptosis in the peripheral blood mononuclear cells of major depressive patients with a high risk for suicide. Am J Med Genet B Neuropsychiatr Genet, 177:388-396.

[65] Mayer EA, Tillisch K, Gupta A (2015). Gut/brain axis and the microbiota. J Clin Invest, 125:926-938.

[66] Ibi M, Liu J, Arakawa N, Kitaoka S, Kawaji A, Matsuda KI, et al. (2017). Depressive-Like Behaviors Are Regulated by NOX1/NADPH Oxidase by Redox Modification of NMDA Receptor 1. J Neurosci, 37:4200-4212.

[67] Koo YS, Kim H, Park JH, Kim MJ, Shin YI, Choi BT, et al. (2018). Indoleamine 2,3-DioxygenaseDependent Neurotoxic Kynurenine Metabolism Contributes to Poststroke Depression Induced in Mice by Ischemic Stroke along with Spatial Restraint Stress. Oxid Med Cell Longev, 2018:2413841.

[68] Kudlow P, Cha DS, Carvalho AF, McIntyre RS (2016). Nitric Oxide and Major Depressive Disorder: Pathophysiology and Treatment Implications. Curr Mol Med, 16:206-215.

[69] Rezin GT, Cardoso MR, Goncalves CL, Scaini G, Fraga DB, Riegel RE, et al. (2008). Inhibition of mitochondrial respiratory chain in brain of rats subjected to an experimental model of depression. Neurochem Int, 53:395-400.

[70] Pasquali MA, Harlow BL, Soares CN, Otto MW, Cohen LS, Minuzzi L, et al. (2018). A longitudinal study of neurotrophic, oxidative, and inflammatory markers in first-onset depression in midlife women. Eur Arch Psychiatry Clin Neurosci, 268:771-781.

[71] Vavakova M, Durackova Z, Trebaticka J (2015). Markers of Oxidative Stress and Neuroprogression in Depression Disorder. Oxid Med Cell Longev, 2015:898393.

[72] Wigner P, Czarny P, Synowiec E, Bijak M, Bialek K, Talarowska M, et al. (2018). Variation of genes involved in oxidative and nitrosative stresses in depression. Eur Psychiatry, 48:38-48.

[73] Jimenez-Fernandez S, Gurpegui M, Diaz-Atienza F, Perez-Costillas L, Gerstenberg M, Correll CU (2015). Oxidative stress and antioxidant parameters in patients with major depressive disorder compared to healthy controls before and after antidepressant treatment: results from a meta-analysis. J Clin Psychiatry, 76:1658-1667.

[74] Moreno-Fernandez AM, Cordero MD, GarridoMaraver J, Alcocer-Gomez E, Casas-Barquero N, Carmona-Lopez MI, et al. (2012). Oral treatment with amitriptyline induces coenzyme $Q$ deficiency and oxidative stress in psychiatric patients. J Psychiatr Res, 46:341-345

[75] Jimenez-Fernandez S, Gurpegui M, Diaz-Atienza F, Perez-Costillas L, Gerstenberg M, Correll CU (2015). Oxidative Stress and Antioxidant Parameters in Patients With Major Depressive Disorder Compared to Healthy Controls Before and After Antidepressant Treatment: Results From a Meta-Analysis. Journal of 
Clinical Psychiatry, 76:1658-+.

[76] Gotschel F, Kern C, Lang S, Sparna T, Markmann C, Schwager J, et al. (2008). Inhibition of GSK3 differentially modulates NF-kappaB, CREB, AP-1 and beta-catenin signaling in hepatocytes, but fails to promote TNF-alpha-induced apoptosis. Exp Cell Res, 314:1351-1366.

[77] Rana AK, Singh D (2018). Targeting glycogen synthase kinase-3 for oxidative stress and neuroinflammation: Opportunities, challenges and future directions for cerebral stroke management. Neuropharmacology, 139:124-136.

[78] Chen X, Liu Y, Zhu J, Lei S, Dong Y, Li L, et al. (2016). GSK-3beta downregulates Nrf2 in cultured cortical neurons and in a rat model of cerebral ischemiareperfusion. Sci Rep, 6:20196.

[79] Qiu J, Nishimura M, Wang Y, Sims JR, Qiu S, Savitz SI, et al. (2008). Early release of HMGB-1 from neurons after the onset of brain ischemia. J Cereb Blood Flow Metab, 28:927-938.

[80] Qiu J, Xu J, Zheng Y, Wei Y, Zhu X, Lo EH, et al. (2010). High-mobility group box 1 promotes metalloproteinase-9 upregulation through Toll-like receptor 4 after cerebral ischemia. Stroke, 41:20772082.

[81] Martin M, Rehani K, Jope RS, Michalek SM (2005). Toll-like receptor-mediated cytokine production is differentially regulated by glycogen synthase kinase 3 . Nat Immunol, 6:777-784.

[82] Iadecola C, Anrather J (2011). The immunology of stroke: from mechanisms to translation. Nat Med, 17:796-808.

[83] Perez-de-Puig I, Miro-Mur F, Ferrer-Ferrer M, Gelpi E, Pedragosa J, Justicia C, et al. (2015). Neutrophil recruitment to the brain in mouse and human ischemic stroke. Acta Neuropathol, 129:239-257.

[84] Zhang Q, Raoof M, Chen Y, Sumi Y, Sursal T, Junger $\mathrm{W}$, et al. (2010). Circulating mitochondrial DAMPs cause inflammatory responses to injury. Nature, 464:104-107.

[85] Kohler O, Krogh J, Mors O, Benros ME (2016). Inflammation in Depression and the Potential for AntiInflammatory Treatment. Curr Neuropharmacol, 14:732-742.

[86] Jiang XP, Elliott RL (2017). Decreased Iron in Cancer Cells and Their Microenvironment Improves Cytolysis of Breast Cancer Cells by Natural Killer Cells. Anticancer Res, 37:2297-2305.

[87] Zhou R, Yazdi AS, Menu P, Tschopp J (2011). A role for mitochondria in NLRP3 inflammasome activation. Nature, 469:221-225.

[88] Alcocer-Gomez E, de Miguel M, Casas-Barquero N, Nunez-Vasco J, Sanchez-Alcazar JA, FernandezRodriguez A, et al. (2014). NLRP3 inflammasome is activated in mononuclear blood cells from patients with major depressive disorder. Brain Behav Immun, 36:111-117.

[89] Roomruangwong C, Anderson G, Berk M, Stoyanov D, Carvalho AF, Maes M (2018). A neuro-immune, neuro-oxidative and neuro-nitrosative model of prenatal and postpartum depression. Prog Neuropsychopharmacol Biol Psychiatry, 81:262-274.

[90] Anderson G (2018). Linking the biological underpinnings of depression: Role of mitochondria interactions with melatonin, inflammation, sirtuins, tryptophan catabolites, DNA repair and oxidative and nitrosative stress, with consequences for classification and cognition. Prog Neuropsychopharmacol Biol Psychiatry, 80:255-266.

[91] Vandenabeele P, Galluzzi L, Vanden Berghe T, Kroemer G (2010). Molecular mechanisms of necroptosis: an ordered cellular explosion. Nat Rev Mol Cell Biol, 11:700-714.

[92] Unal-Cevik I, Kilinc M, Can A, Gursoy-Ozdemir Y, Dalkara T (2004). Apoptotic and necrotic death mechanisms are concomitantly activated in the same cell after cerebral ischemia. Stroke, 35:2189-2194.

[93] Wang P, Shao BZ, Deng Z, Chen S, Yue Z, Miao CY (2018). Autophagy in ischemic stroke. Prog Neurobiol, 163-164:98-117.

[94] Culmsee C, Zhu C, Landshamer S, Becattini B, Wagner E, Pellecchia M, et al. (2005). Apoptosisinducing factor triggered by poly(ADP-ribose) polymerase and Bid mediates neuronal cell death after oxygen-glucose deprivation and focal cerebral ischemia. J Neurosci, 25:10262-10272.

[95] Yu A, Zhang T, Zhong W, Duan H, Wang S, Ye P, et al. (2017). miRNA-144 induces microglial autophagy and inflammation following intracerebral hemorrhage. Immunol Lett, 182:18-23.

[96] Shen X, Ma L, Dong W, Wu Q, Gao Y, Luo C, et al. (2016). Autophagy regulates intracerebral hemorrhage induced neural damage via apoptosis and NF-kappaB pathway. Neurochem Int, 96:100-112.

[97] McKernan DP, Dinan TG, Cryan JF (2009). "Killing the Blues": a role for cellular suicide (apoptosis) in depression and the antidepressant response? Prog Neurobiol, 88:246-263.

[98] Takayama S, Sato T, Krajewski S, Kochel K, Irie S, Millan JA, et al. (1995). Cloning and functional analysis of BAG-1: a novel Bcl-2-binding protein with anti-cell death activity. Cell, 80:279-284.

[99] Harlan J, Chen Y, Gubbins E, Mueller R, Roch JM, Walter K, et al. (2006). Variants in Apaf-1 segregating with major depression promote apoptosome function. Mol Psychiatry, 11:76-85.

[100] Dumitrescu L, Popescu-Olaru I, Cozma L, Tulba D, Hinescu ME, Ceafalan LC, et al. (2018). Oxidative Stress and the Microbiota-Gut-Brain Axis. Oxidative Medicine and Cellular Longevity.

[101] Bonaz B, Bazin T, Pellissier S (2018). The Vagus Nerve at the Interface of the Microbiota-Gut-Brain Axis. Frontiers in Neuroscience, 12.

[102] Martino R, Foley N, Bhogal S, Diamant N, Speechley M, Teasell R (2005). Dysphagia after stroke: incidence, diagnosis, and pulmonary complications. Stroke, 36:2756-2763.

[103] Harari D, Coshall C, Rudd AG, Wolfe CD (2003). New-onset fecal incontinence after stroke: prevalence, natural history, risk factors, and impact. Stroke, 
34:144-150.

[104] O'Donnell MJ, Kapral MK, Fang J, Saposnik G, Eikelboom JW, Oczkowski W, et al. (2008). Gastrointestinal bleeding after acute ischemic stroke. Neurology, 71:650-655.

[105] Su YJ, Zhang XY, Zeng JS, Pei Z, Cheung RTF, Zhou QP, et al. (2009). New-Onset Constipation at Acute Stage After First Stroke Incidence, Risk Factors, and Impact on the Stroke Outcome. Stroke, 40:1304-1309.

[106] Wen SW, Wong CHY (2017). An unexplored brain-gut microbiota axis in stroke. Gut Microbes, 8:601-606.

[107] Benakis C, Brea D, Caballero S, Faraco G, Moore J, Murphy M, et al. (2016). Commensal microbiota affects ischemic stroke outcome by regulating intestinal gammadelta T cells. Nat Med, 22:516-523.

[108] Rhee SH, Pothoulakis C, Mayer EA (2009). Principles and clinical implications of the brain-gut-enteric microbiota axis. Nat Rev Gastroenterol Hepatol, 6:306-314.

[109] Zheng P, Zeng B, Zhou C, Liu M, Fang Z, Xu X, et al. (2016). Gut microbiome remodeling induces depressive-like behaviors through a pathway mediated by the host's metabolism. Molecular Psychiatry, 21:786-796.

[110] Slyepchenko A, Maes M, Jacka FN, Kohler CA, Barichello T, McIntyre RS, et al. (2017). Gut Microbiota, Bacterial Translocation, and Interactions with Diet: Pathophysiological Links between Major Depressive Disorder and Non-Communicable Medical Comorbidities. Psychother Psychosom, 86:31-46.

[111] Willey JZ, Moon YP, Sacco RL, Greenlee H, Diaz KM, Wright CB, et al. (2017). Physical inactivity is a strong risk factor for stroke in the oldest old: Findings from a multi-ethnic population (the Northern Manhattan Study). International Journal of Stroke, 12:197-200.

[112] Ay H, Arsava EM, Andsberg G, Benner T, Brown RD, Jr., Chapman SN, et al. (2014). Pathogenic ischemic stroke phenotypes in the NINDS-stroke genetics network. Stroke, 45:3589-3596

[113] Howard G, Goff DC (2012). Population shifts and the future of stroke: forecasts of the future burden of stroke. Ann N Y Acad Sci, 1268:14-20.

[114] Sjoberg L, Karlsson B, Atti AR, Skoog I, Fratiglioni L, Wang HX (2017). Prevalence of depression: Comparisons of different depression definitions in population-based samples of older adults. J Affect Disord, 221:123-131.

[115] Ames BN, Shigenaga MK, Hagen TM (1993). Oxidants, antioxidants, and the degenerative diseases of aging. Proc Natl Acad Sci U S A, 90:7915-7922.

[116] Floyd RA, Hensley K (2002). Oxidative stress in brain aging. Implications for therapeutics of neurodegenerative diseases. Neurobiol Aging, 23:795807.

[117] Bettio LEB, Rajendran L, Gil-Mohapel J (2017). The effects of aging in the hippocampus and cognitive decline. Neurosci Biobehav Rev, 79:66-86.

[118] Wu Z, Yu J, Zhu A, Nakanishi H (2016). Nutrients, Microglia Aging, and Brain Aging. Oxid Med Cell Longev, 2016:7498528.
Poulose SM, Miller MG, Scott T, Shukitt-Hale B (2017). Nutritional Factors Affecting Adult Neurogenesis and Cognitive Function. Adv Nutr, 8:804-811.

[120] Corenblum MJ, Ray S, Remley QW, Long M, Harder B, Zhang DD, et al. (2016). Reduced Nrf2 expression mediates the decline in neural stem cell function during a critical middle-age period. Aging Cell, 15:725-736.

[121] Maher P (2018). Potentiation of glutathione loss and nerve cell death by the transition metals iron and copper: Implications for age-related neurodegenerative diseases. Free Radic Biol Med, 115:92-104

[122] Mattson MP, Arumugam TV (2018). Hallmarks of Brain Aging: Adaptive and Pathological Modification by Metabolic States. Cell Metab, 27:1176-1199.

[123] Ham PB, 3rd, Raju R (2017). Mitochondrial function in hypoxic ischemic injury and influence of aging. Prog Neurobiol, 157:92-116.

[124] Rzechorzek W, Zhang H, Buckley BK, Hua K, Pomp D, Faber JE (2017). Aerobic exercise prevents rarefaction of pial collaterals and increased stroke severity that occur with aging. J Cereb Blood Flow Metab, 37:3544-3555.

[125] Graham SH, Liu H (2017). Life and death in the trash heap: The ubiquitin proteasome pathway and UCHL1 in brain aging, neurodegenerative disease and cerebral Ischemia. Ageing Res Rev, 34:30-38.

[126] Badan I, Buchhold B, Hamm A, Gratz M, Walker LC, Platt D, et al. (2003). Accelerated glial reactivity to stroke in aged rats correlates with reduced functional recovery. J Cereb Blood Flow Metab, 23:845-854.

[127] Campuzano O, Castillo-Ruiz MM, Acarin L, Castellano B, Gonzalez B (2009). Increased levels of proinflammatory cytokines in the aged rat brain attenuate injury-induced cytokine response after excitotoxic damage. J Neurosci Res, 87:2484-2497.

[128] Camacho E, LoPresti MA, Bruce S, Lin D, Abraham M, Appelboom G, et al. (2015). The role of age in intracerebral hemorrhages. J Clin Neurosci, 22:18671870.

[129] Brown PJ, Rutherford BR, Yaffe K, Tandler JM, Ray JL, Pott E, et al. (2016). The Depressed Frail Phenotype: The Clinical Manifestation of Increased Biological Aging. Am J Geriatr Psychiatry, 24:10841094.

[130] Karabatsiakis A, Bock C, Salinas-Manrique J, Kolassa S, Calzia E, Dietrich DE, et al. (2014). Mitochondrial respiration in peripheral blood mononuclear cells correlates with depressive subsymptoms and severity of major depression. Transl Psychiatry, 4:e397.

[131] Geerlings MI, Gerritsen L (2017). Late-Life Depression, Hippocampal Volumes, and Hypothalamic-Pituitary-Adrenal Axis Regulation: A Systematic Review and Meta-analysis. Biol Psychiatry, 82:339-350.

[132] Volkow ND, Gur RC, Wang GJ, Fowler JS, Moberg PJ, Ding YS, et al. (1998). Association between decline in brain dopamine activity with age and cognitive and 
motor impairment in healthy individuals. American Journal of Psychiatry, 155:344-349.

[133] Troiano AR, Schulzer M, de la Fuente-Fernandez R, Mak E, McKenzie J, Sossi V, et al. (2010). Dopamine transporter PET in normal aging: dopamine transporter decline and its possible role in preservation of motor function. Synapse, 64:146-151.

[134] van Dyck CH, Avery RA, MacAvoy MG, Marek KL, Quinlan DM, Baldwin RM, et al. (2008). Striatal dopamine transporters correlate with simple reaction time in elderly subjects. Neurobiol Aging, 29:12371246.

[135] Visser M, Pahor M, Taaffe DR, Goodpaster BH, Simonsick EM, Newman AB, et al. (2002). Relationship of interleukin-6 and tumor necrosis factor-alpha with muscle mass and muscle strength in elderly men and women: the Health ABC Study. J Gerontol A Biol Sci Med Sci, 57:M326-332.

[136] Steptoe A, Deaton A, Stone AA (2015). Subjective wellbeing, health, and ageing. Lancet, 385:640-648.

[137] Ghimire S, Baral BK, Pokhrel BR, Pokhrel A, Acharya A, Amatya D, et al. (2018). Depression, malnutrition, and health-related quality of life among Nepali older patients. Bmc Geriatrics, 18.

[138] Araujo JR, Martel F, Borges N, Araujo JM, Keating E (2015). Folates and aging: Role in mild cognitive impairment, dementia and depression. Ageing Res Rev, 22:9-19.

[139] Mendelsohn AR, Larrick JW (2017). The NAD+/PARP1/SIRT1 Axis in Aging. Rejuvenation Res, 20:244-247.

[140] Xie Q, Peng S, Tao L, Ruan H, Yang Y, Li TM, et al. (2014). E2F transcription factor 1 regulates cellular and organismal senescence by inhibiting Forkhead box O transcription factors. J Biol Chem, 289:3420534213.

[141] Gonzalez-Giraldo Y, Forero DA, Echeverria V, Gonzalez J, Avila-Rodriguez M, Garcia-Segura LM, et al. (2016). Neuroprotective effects of the catalytic subunit of telomerase: A potential therapeutic target in the central nervous system. Ageing Res Rev, 28:37-45.

[142] Duffy SL, Lagopoulos J, Cockayne N, Hermens DF, Hickie IB, Naismith SL (2015). Oxidative stress and depressive symptoms in older adults: A magnetic resonance spectroscopy study. J Affect Disord, 180:29-35.

[143] Kok RM, Reynolds CF, 3rd (2017). Management of Depression in Older Adults: A Review. JAMA, 317:2114-2122.

[144] Cipriani A, Furukawa TA, Salanti G, Chaimani A, Atkinson LZ, Ogawa Y, et al. (2018). Comparative efficacy and acceptability of 21 antidepressant drugs for the acute treatment of adults with major depressive disorder: a systematic review and network metaanalysis. Lancet, 391:1357-1366.

[145] Hu L, Chen W, Tian F, Yuan C, Wang H, Yue H (2018). Neuroprotective role of fucoxanthin against cerebral ischemic/reperfusion injury through activation of Nrf2/HO-1 signaling. Biomed Pharmacother, 106:1484-1489.
[146] Zhang W, Wei R, Zhang L, Tan Y, Qian C (2017). Sirtuin 6 protects the brain from cerebral ischemia/reperfusion injury through NRF2 activation. Neuroscience, 366:95-104.

[147] Guo C, Wang S, Duan J, Jia N, Zhu Y, Ding Y, et al. (2017). Protocatechualdehyde Protects Against Cerebral Ischemia-Reperfusion-Induced Oxidative Injury Via Protein Kinase Cepsilon/Nrf2/HO-1 Pathway. Mol Neurobiol, 54:833-845.

[148] Yang Z, Weian C, Susu H, Hanmin W (2016). Protective effects of mangiferin on cerebral ischemiareperfusion injury and its mechanisms. Eur $\mathrm{J}$ Pharmacol, 771:145-151.

[149] Liu L, Vollmer MK, Ahmad AS, Fernandez VM, Kim H, Dore S (2019). Pretreatment with Korean red ginseng or dimethyl fumarate attenuates reactive gliosis and confers sustained neuroprotection against cerebral hypoxic-ischemic damage by an Nrf2dependent mechanism. Free Radical Biology and Medicine, 131:98-114.

[150] Ding Y, Chen MC, Wang MM, Li YW, Wen AD (2015). Posttreatment with 11-Keto-beta-Boswellic Acid Ameliorates Cerebral Ischemia-Reperfusion Injury: Nrf2/HO-1 Pathway as a Potential Mechanism. Molecular Neurobiology, 52:1430-1439.

[151] Ashabi G, Khalaj L, Khodagholi F, Goudarzvand M, Sarkaki A (2015). Pre-treatment with metformin activates Nrf2 antioxidant pathways and inhibits inflammatory responses through induction of AMPK after transient global cerebral ischemia. Metab Brain Dis, 30:747-754.

[152] Shi H, Jing X, Wei X, Perez RG, Ren M, Zhang X, et al. (2015). S-allyl cysteine activates the Nrf2dependent antioxidant response and protects neurons against ischemic injury in vitro and in vivo. $\mathrm{J}$ Neurochem, 133:298-308.

[153] Singh D, Reeta KH, Sharma U, Jagannathan NR, Dinda AK, Gupta YK (2019). Neuro-protective effect of monomethyl fumarate on ischemia reperfusion injury in rats: Role of $\mathrm{Nrf2/HO1}$ pathway in periinfarct region. Neurochem Int, 126:96-108.

[154] Cui YJ, Amarsanaa K, Lee JH, Rhim JK, Kwon JM, Kim SH, et al. (2019). Neuroprotective mechanisms of dieckol against glutamate toxicity through reactive oxygen species scavenging and nuclear factor-like 2/heme oxygenase-1 pathway. Korean Journal of Physiology \& Pharmacology, 23:121-130.

[155] Lin R, Cai J, Kostuk EW, Rosenwasser R, Iacovitti L (2016). Fumarate modulates the immune/inflammatory response and rescues nerve cells and neurological function after stroke in rats. J Neuroinflammation, 13:269.

[156] Ya BL, Liu Q, Li HF, Cheng HJ, Yu T, Chen L, et al. (2018). Uric Acid Protects against Focal Cerebral Ischemia/Reperfusion-Induced Oxidative Stress via Activating Nrf2 and Regulating Neurotrophic Factor Expression. Oxid Med Cell Longev, 2018:6069150.

[157] Wang Y, Huang Y, Xu Y, Ruan W, Wang H, Zhang Y, et al. (2018). A Dual AMPK/Nrf2 Activator Reduces Brain Inflammation After Stroke by Enhancing 
Microglia M2 Polarization. Antioxid Redox Signal, 28:141-163.

[158] Yen TL, Chen RJ, Jayakumar T, Lu WJ, Hsieh CY, Hsu MJ, et al. (2016). Andrographolide stimulates p38 mitogen-activated protein kinase-nuclear factor erythroid-2-related factor 2-heme oxygenase 1 signaling in primary cerebral endothelial cells for definite protection against ischemic stroke in rats. Transl Res, 170:57-72.

[159] Lee CT, Yu LE, Wang JY (2016). Nitroxide antioxidant as a potential strategy to attenuate the oxidative/nitrosative stress induced by hydrogen peroxide plus nitric oxide in cultured neurons. Nitric Oxide-Biology and Chemistry, 54:38-50.

[160] Kuo PC, Yu IC, Scofield BA, Brown DA, Curfman ET, Paraiso HC, et al. (2017). 3H-1,2-Dithiole-3-thione as a novel therapeutic agent for the treatment of ischemic stroke through Nrf2 defense pathway. Brain Behav Immun, 62:180-192.

[161] Chen N, Zhou Z, Li J, Li B, Feng J, He D, et al. (2018). 3-n-butylphthalide exerts neuroprotective effects by enhancing anti-oxidation and attenuating mitochondrial dysfunction in an in vitro model of ischemic stroke. Drug Des Devel Ther, 12:4261-4271.

[162] Wu JZ, Jin Z, Yang XR, Yan LJ (2018). Post-ischemic administration of 5-methoxyindole-2-carboxylic acid at the onset of reperfusion affords neuroprotection against stroke injury by preserving mitochondrial function and attenuating oxidative stress. Biochemical and Biophysical Research Communications, 497:444450.

[163] Yang Y, Jiang S, Dong Y, Fan C, Zhao L, Yang X, et al. (2015). Melatonin prevents cell death and mitochondrial dysfunction via a SIRT1-dependent mechanism during ischemic-stroke in mice. J Pineal Res, 58:61-70.

[164] Andrabi SS, Parvez S, Tabassum H (2017). Progesterone induces neuroprotection following reperfusion-promoted mitochondrial dysfunction after focal cerebral ischemia in rats. Dis Model Mech, 10:787-796.

[165] Silachev DN, Plotnikov EY, Pevzner IB, Zorova LD, Balakireva AV, Gulyaev MV, et al. (2018). Neuroprotective Effects of Mitochondria-Targeted Plastoquinone in a Rat Model of Neonatal Hypoxic(-)Ischemic Brain Injury. Molecules, 23.

[166] Chen M, Zou W, Chen M, Cao L, Ding J, Xiao W, et al. (2018). Ginkgolide $\mathrm{K}$ promotes angiogenesis in a middle cerebral artery occlusion mouse model via activating JAK2/STAT3 pathway. Eur J Pharmacol, 833:221-229.

[167] Xie YZ, Zhang XJ, Zhang C, Yang Y, He JN, Chen YX (2019). Protective effects of leonurine against ischemic stroke in mice by activating nuclear factor erythroid 2-related factor 2 pathway. CNS Neurosci Ther.

[168] Li H, Wang P, Huang F, Jin J, Wu H, Zhang B, et al. (2018). Astragaloside IV protects blood-brain barrier integrity from LPS-induced disruption via activating Nrf2 antioxidant signaling pathway in mice. Toxicol
Appl Pharmacol, 340:58-66.

[169] Chen Z, Mao X, Liu A, Gao X, Chen X, Ye M, et al. (2015). Osthole, a natural coumarin improves cognitive impairments and $\mathrm{BBB}$ dysfunction after transient global brain ischemia in $\mathrm{C} 57 \mathrm{BL} / 6 \mathrm{~J}$ mice: involvement of Nrf2 pathway. Neurochem Res, 40:186-194.

[170] Hu S, Wu Y, Zhao B, Hu H, Zhu B, Sun Z, et al. (2018). Panax notoginseng Saponins Protect Cerebral Microvascular Endothelial Cells against OxygenGlucose Deprivation/Reperfusion-Induced Barrier Dysfunction via Activation of PI3K/Akt/Nrf2 Antioxidant Signaling Pathway. Molecules, 23.

[171] Li L, Yang N, Nin L, Zhao Z, Chen L, Yu J, et al. (2015). Chinese herbal medicine formula tao hong si wu decoction protects against cerebral ischemiareperfusion injury via PI3K/Akt and the Nrf2 signaling pathway. J Nat Med, 69:76-85.

[172] Zhou F, Wang M, Ju J, Wang Y, Liu Z, Zhao X, et al. (2019). Schizandrin A protects against cerebral ischemia-reperfusion injury by suppressing inflammation and oxidative stress and regulating the AMPK/Nrf2 pathway regulation. Am J Transl Res, 11:199-209.

[173] Kwon YW, Cheon SY, Park SY, Song J, Lee JH (2017). Tryptanthrin Suppresses the Activation of the LPSTreated BV2 Microglial Cell Line via Nrf2/HO-1 Antioxidant Signaling. Front Cell Neurosci, 11:18.

[174] Yang MY, Yu QL, Huang YS, Yang G (2019). Neuroprotective effects of andrographolide derivative CX-10 in transient focal ischemia in rat: Involvement of Nrf2/AE and TLR/NF-kappaB signaling. Pharmacol Res, 144:227-234.

[175] Li C, Zhang WJ, Frei B (2016). Quercetin inhibits LPS-induced adhesion molecule expression and oxidant production in human aortic endothelial cells by $\mathrm{p} 38$-mediated Nrf2 activation and antioxidant enzyme induction. Redox Biol, 9:104-113.

[176] Zhu SL, Tang SY, Su F (2018). Dioscin inhibits ischemic stroke-induced inflammation through inhibition of the TLR4/MyD88/NF-B signaling pathway in a rat model. Molecular Medicine Reports, 17:660-666.

[177] Hou Y, Wang Y, He Q, Li L, Xie H, Zhao Y, et al. (2018). Nrf2 inhibits NLRP3 inflammasome activation through regulating Trx1/TXNIP complex in cerebral ischemia reperfusion injury. Behav Brain Res, 336:32-39.

[178] Wang WM, Liu Z, Liu AJ, Wang YX, Wang HG, An D, et al. (2015). The Zinc Ion Chelating Agent TPEN Attenuates Neuronal Death/apoptosis Caused by Hypoxia/ischemia Via Mediating the Pathophysiological Cascade Including Excitotoxicity, Oxidative Stress, and Inflammation. CNS Neurosci Ther, 21:708-717.

[179] Yu G, Liang Y, Zheng S, Zhang H (2018). Inhibition of Myeloperoxidase by N-Acetyl Lysyltyrosylcysteine Amide Reduces Oxidative Stress-Mediated Inflammation, Neuronal Damage, and Neural Stem Cell Injury in a Murine Model of Stroke. J Pharmacol 
Exp Ther, 364:311-322.

[180] Cai M, Guo YX, Wang SQ, Wei HD, Sun SS, Zhao GC, et al. (2017). Tanshinone IIA Elicits Neuroprotective Effect Through Activating the Nuclear Factor Erythroid 2-Related Factor-Dependent Antioxidant Response. Rejuvenation Research, 20:286-297.

[181] Dou Z, Rong X, Zhao E, Zhang L, Lv Y (2019). Neuroprotection of Resveratrol Against Focal Cerebral Ischemia/Reperfusion Injury in Mice Through a Mechanism Targeting Gut-Brain Axis. Cell Mol Neurobiol, 39:883-898.

[182] Yuen CM, Yeh KH, Wallace CG, Chen KH, Lin HS, Sung PH, et al. (2017). EPO-cyclosporine combination therapy reduced brain infarct area in rat after acute ischemic stroke: role of innate immuneinflammatory response, micro-RNAs and MAPK family signaling pathway. Am J Transl Res, 9:16511666.

[183] Zhao Q, Wang X, Chen A, Cheng X, Zhang G, Sun J, et al. (2018). Rhein protects against cerebral ischemic/reperfusioninduced oxidative stress and apoptosis in rats. Int J Mol Med, 41:2802-2812.

[184] Qian H, Ding X, Zhang J, Mao F, Sun Z, Jia H, et al. (2017). Cancer stemness and metastatic potential of the novel tumor cell line K3: an inner mutated cell of bone marrow-derived mesenchymal stem cells. Oncotarget.

[185] Xia D, Zhang Z, Zhao Y (2018). Acteoside Attenuates Oxidative Stress and Neuronal Apoptosis in Rats with Focal Cerebral Ischemia-Reperfusion Injury. Biol Pharm Bull, 41:1645-1651.

[186] Meng X, Xie W, Xu Q, Liang T, Xu X, Sun G, et al. (2018). Neuroprotective Effects of Radix Scrophulariae on Cerebral Ischemia and Reperfusion Injury via MAPK Pathways. Molecules, 23.

[187] Tsai YR, Chang CF, Lai JH, Wu JC, Chen YH, Kang SJ, et al. (2018). Pomalidomide Ameliorates $\mathrm{H}(2) \mathrm{O}(2)$-Induced Oxidative Stress Injury and Cell Death in Rat Primary Cortical Neuronal Cultures by Inducing Anti-Oxidative and Anti-Apoptosis Effects. Int J Mol Sci, 19.

[188] Sun J, Ling ZX, Wang FY, Chen WQ, Li HX, Jin JT, et al. (2016). Clostridium butyricum pretreatment attenuates cerebral ischemia/reperfusion injury in mice via anti-oxidation and anti-apoptosis. Neuroscience Letters, 613:30-35.

[189] Wang BD, Guo H, Li X, Yue L, Liu HX, Zhao L, et al. (2018). Adiponectin Attenuates Oxygen-Glucose Deprivation-Induced Mitochondrial Oxidative Injury and Apoptosis in Hippocampal HT22 Cells via the JAK2/STAT3 Pathway. Cell Transplantation, 27:17311743.

[190] Xu Y, Wang Y, Wang G, Ye X, Zhang J, Cao G, et al. (2017). YiQiFuMai Powder Injection Protects against Ischemic Stroke via Inhibiting Neuronal Apoptosis and PKCdelta/Drp1-Mediated Excessive Mitochondrial Fission. Oxid Med Cell Longev, 2017:1832093.

[191] Nan W, Zhonghang X, Keyan C, Tongtong L, Wanshu G, Zhongxin X (2018). Epigallocatechin-3-Gallate
Reduces Neuronal Apoptosis in Rats after Middle Cerebral Artery Occlusion Injury via PI3K/AKT/eNOS Signaling Pathway. Biomed Res Int, 2018:6473580.

[192] Raghavan A, Shah ZA (2015). Withania somnifera Improves Ischemic Stroke Outcomes by Attenuating PARP1-AIF-Mediated Caspase-Independent Apoptosis. Mol Neurobiol, 52:1093-1105.

[193] Shen K, Wang Y, Zhang Y, Zhou H, Song Y, Cao Z, et al. (2015). Cocktail of Four Active Components Derived from Sheng Mai San Inhibits Hydrogen Peroxide-Induced PC12 Cell Apoptosis Linked with the Caspase-3/ROCK1/MLC Pathway. Rejuvenation Res, 18:517-527.

[194] Xu XH, Li GL, Wang BA, Qin Y, Bai SR, Rong J, et al. (2015). Diallyl trisufide protects against oxygen glucose deprivation -induced apoptosis by scavenging free radicals via the PI3K/Akt -mediated Nrf2/HO-1 signaling pathway in B35 neural cells. Brain Res, 1614:38-50.

[195] Zhang K, Tu M, Gao W, Cai X, Song F, Chen Z, et al. (2019). Hollow Prussian Blue Nanozymes Drive Neuroprotection against Ischemic Stroke via Attenuating Oxidative Stress, Counteracting Inflammation, and Suppressing Cell Apoptosis. Nano Lett, 19:2812-2823.

[196] Li C, Wang X, Cheng F, Du X, Yan J, Zhai C, et al. (2019). Geniposide protects against hypoxia/reperfusion-induced blood-brain barrier impairment by increasing tight junction protein expression and decreasing inflammation, oxidative stress, and apoptosis in an in vitro system. Eur $\mathrm{J}$ Pharmacol, 854:224-231.

[197] Li W, Suwanwela NC, Patumraj S (2016). Curcumin by down-regulating NF-kB and elevating Nrf2, reduces brain edema and neurological dysfunction after cerebral I/R. Microvasc Res, 106:117-127.

[198] Wicha P, Tocharus J, Janyou A, Jittiwat J, Changtam C, Suksamrarn A, et al. (2017). Hexahydrocurcumin protects against cerebral ischemia/reperfusion injury, attenuates inflammation, and improves antioxidant defenses in a rat stroke model. PLoS One, 12:e0189211.

[199] Dai SH, Chen T, Li X, Yue KY, Luo P, Yang LK, et al. (2017). Sirt3 confers protection against neuronal ischemia by inducing autophagy: Involvement of the AMPK-mTOR pathway. Free Radic Biol Med, 108:345-353.

[200] Wang P, Xu TY, Wei K, Guan YF, Wang X, Xu H, et al. (2014). ARRB1/beta-arrestin-1 mediates neuroprotection through coordination of BECN1dependent autophagy in cerebral ischemia. Autophagy, 10:1535-1548.

[201] Jiang J, Dai J, Cui H (2018). Vitexin reverses the autophagy dysfunction to attenuate MCAO-induced cerebral ischemic stroke via mTOR/Ulk1 pathway. Biomed Pharmacother, 99:583-590.

[202] Wang M, Li YJ, Ding Y, Zhang HN, Sun T, Zhang K, et al. (2016). Silibinin Prevents Autophagic Cell Death upon Oxidative Stress in Cortical Neurons and 
Cerebral Ischemia-Reperfusion Injury. Molecular Neurobiology, 53:932-943.

[203] Zhao Y, Huang G, Chen S, Gou Y, Dong Z, Zhang X (2016). Folic acid deficiency increases brain cell injury via autophagy enhancement after focal cerebral ischemia. J Nutr Biochem, 38:41-49.

[204] Chiu BY, Chang CP, Lin JW, Yu JS, Liu WP, Hsu YC, et al. (2014). Beneficial effect of astragalosides on stroke condition using PC12 cells under oxygen glucose deprivation and reperfusion. Cell Mol Neurobiol, 34:825-837.

[205] Dai Y, Zhang H, Zhang J, Yan M (2018). Isoquercetin attenuates oxidative stress and neuronal apoptosis after ischemia/reperfusion injury via Nrf2-mediated inhibition of the NOX4/ROS/NF-kappaB pathway. Chem Biol Interact, 284:32-40.

[206] Wang CP, Shi YW, Tang M, Zhang XC, Gu Y, Liang $\mathrm{XM}$, et al. (2017). Isoquercetin Ameliorates Cerebral Impairment in Focal Ischemia Through AntiOxidative, Anti-Inflammatory, and Anti-Apoptotic Effects in Primary Culture of Rat Hippocampal Neurons and Hippocampal CA1 Region of Rats. Mol Neurobiol, 54:2126-2142.

[207] Fu B, Zeng Q, Zhang Z, Qian M, Chen J, Dong W, et al. (2019). Epicatechin Gallate Protects HBMVECs from Ischemia/Reperfusion Injury through Ameliorating Apoptosis and Autophagy and Promoting Neovascularization. Oxid Med Cell Longev, 2019:7824684.

[208] Altermann CDC, Souza MA, Schimidt HL, Izaguirry AP, Martins A, Garcia A, et al. (2017). Short-term green tea supplementation prevents recognition memory deficits and ameliorates hippocampal oxidative stress induced by different stroke models in rats. Brain Res Bull, 131:78-84.

[209] Sosa PM, de Souza MA, Mello-Carpes PB (2018). Green Tea and Red Tea from Camellia sinensis Partially Prevented the Motor Deficits and Striatal Oxidative Damage Induced by Hemorrhagic Stroke in Rats. Neural Plast, 2018:5158724.

[210] Alhadidi Q, Nash KM, Alaqel S, Sayeed MSB, Shah ZA (2018). Cofilin Knockdown Attenuates Hemorrhagic Brain Injury-induced Oxidative Stress and Microglial Activation in Mice. Neuroscience, 383:33-45.

[211] Zhang P, Wang T, Zhang D, Zhang Z, Yuan S, Zhang $\mathrm{J}$, et al. (2019). Exploration of MST1-Mediated Secondary Brain Injury Induced by Intracerebral Hemorrhage in Rats via Hippo Signaling Pathway. Transl Stroke Res.

[212] Huang J, Jiang Q (2019). Dexmedetomidine Protects Against Neurological Dysfunction in a Mouse Intracerebral Hemorrhage Model by Inhibiting Mitochondrial Dysfunction-Derived Oxidative Stress. J Stroke Cerebrovasc Dis, 28:1281-1289.

[213] Shi J, Wu G, Zou X, Jiang K (2017). Oleuropein protects intracerebral hemorrhage-induced disruption of blood-brain barrier through alleviation of oxidative stress. Pharmacol Rep, 69:1206-1212.

[214] Wang S, Li D, Huang C, Wan Y, Wang J, Zan X, et al.
(2018). Overexpression of adiponectin alleviates intracerebral hemorrhage-induced brain injury in rats via suppression of oxidative stress. Neurosci Lett, 681:110-116.

[215] Zeng J, Chen Y, Ding R, Feng L, Fu Z, Yang S, et al. (2017). Isoliquiritigenin alleviates early brain injury after experimental intracerebral hemorrhage via suppressing ROS- and/or NF-kappaB-mediated NLRP3 inflammasome activation by promoting Nrf2 antioxidant pathway. J Neuroinflammation, 14:119.

[216] Zheng J, Shi L, Liang F, Xu W, Li T, Gao L, et al. (2018). Sirt3 Ameliorates Oxidative Stress and Mitochondrial Dysfunction After Intracerebral Hemorrhage in Diabetic Rats. Front Neurosci, 12:414.

[217] Xu W, Li T, Gao L, Lenahan C, Zheng J, Yan J, et al. (2019). Sodium Benzoate Attenuates Secondary Brain Injury by Inhibiting Neuronal Apoptosis and Reducing Mitochondria-Mediated Oxidative Stress in a Rat Model of Intracerebral Hemorrhage: Possible Involvement of DJ-1/Akt/IKK/NFkappaB Pathway. Front Mol Neurosci, 12:105.

[218] Xie RX, Li DW, Liu XC, Yang MF, Fang J, Sun BL, et al. (2017). Carnosine Attenuates Brain Oxidative Stress and Apoptosis After Intracerebral Hemorrhage in Rats. Neurochem Res, 42:541-551.

[219] Qi B, Hu L, Zhu L, Shang L, Wang X, Liu N, et al. (2017). Metformin Attenuates Neurological Deficit after Intracerebral Hemorrhage by Inhibiting Apoptosis, Oxidative Stress and Neuroinflammation in Rats. Neurochem Res, 42:2912-2920.

[220] Wei N, Wei Y, Li B, Pang L (2017). Baicalein Promotes Neuronal and Behavioral Recovery After Intracerebral Hemorrhage Via Suppressing Apoptosis, Oxidative Stress and Neuroinflammation. Neurochem Res, 42:1345-1353.

[221] Choi KS, Kim HJ, Do SH, Hwang SJ, Yi HJ (2018). Neuroprotective effects of hydrogen inhalation in an experimental rat intracerebral hemorrhage model. Brain Res Bull, 142:122-128.

[222] Xi Z, Hu X, Chen X, Yang Y, Ren J, Wang B, et al. (2019). Protocatechuic acid exerts protective effects via suppression of the P38/JNK- NF-kappaB signalling pathway in an experimental mouse model of intracerebral haemorrhage. Eur J Pharmacol, 854:128138.

[223] Karuppagounder SS, Alim I, Khim SJ, Bourassa MW, Sleiman SF, John R, et al. (2016). Therapeutic targeting of oxygen-sensing prolyl hydroxylases abrogates ATF4-dependent neuronal death and improves outcomes after brain hemorrhage in several rodent models. Sci Transl Med, 8:328ra329.

[224] Liu Y, Qiu J, Wang Z, You W, Wu L, Ji C, et al. (2015). Dimethylfumarate alleviates early brain injury and secondary cognitive deficits after experimental subarachnoid hemorrhage via activation of Keap1Nrf2-ARE system. J Neurosurg, 123:915-923.

[225] Erdi F, Keskin F, Esen H, Kaya B, Feyzioglu B, Kilinc I, et al. (2016). Telmisartan ameliorates oxidative stress and subarachnoid haemorrhage-induced cerebral vasospasm. Neurological Research, 38:224- 
231.

[226] Aladag MA, Turkoz Y, Parlakpinar H, Gul M (2017). Nebivolol attenuates cerebral vasospasm both by increasing endothelial nitric oxide and by decreasing oxidative stress in an experimental subarachnoid haemorrhage. British Journal of Neurosurgery, 31:439-445.

[227] Cai J, Xu D, Bai X, Pan R, Wang B, Sun S, et al. (2017). Curcumin mitigates cerebral vasospasm and early brain injury following subarachnoid hemorrhage via inhibiting cerebral inflammation. Brain Behav, 7:e00790.

[228] Liu H, Zhao L, Yue L, Wang B, Li X, Guo H, et al. (2017). Pterostilbene Attenuates Early Brain Injury Following Subarachnoid Hemorrhage via Inhibition of the NLRP3 Inflammasome and Nox2-Related Oxidative Stress. Mol Neurobiol, 54:5928-5940.

[229] Han Y, Zhang T, Su J, Zhao Y, Chenchen, Wang, et al. (2017). Apigenin attenuates oxidative stress and neuronal apoptosis in early brain injury following subarachnoid hemorrhage. J Clin Neurosci, 40:157162.

[230] Lu Y, Zhang XS, Zhou XM, Gao YY, Chen CL, Liu JP, et al. (2019). Peroxiredoxin $1 / 2$ protects brain against $\mathrm{H} 2 \mathrm{O} 2$-induced apoptosis after subarachnoid hemorrhage. FASEB J, 33:3051-3062.

[231] Zhang T, Wu P, Zhang JH, Li Y, Xu S, Wang C, et al. (2018). Docosahexaenoic Acid Alleviates Oxidative Stress-Based Apoptosis Via Improving Mitochondrial Dynamics in Early Brain Injury After Subarachnoid Hemorrhage. Cell Mol Neurobiol, 38:1413-1423.

[232] Cui Y, Duan X, Li H, Dang B, Yin J, Wang Y, et al. (2016). Hydrogen Sulfide Ameliorates Early Brain Injury Following Subarachnoid Hemorrhage in Rats. Mol Neurobiol, 53:3646-3657.

[233] Zhang ZY, Yang MF, Wang T, Li DW, Liu YL, Zhang $\mathrm{JH}$, et al. (2015). Cysteamine alleviates early brain injury via reducing oxidative stress and apoptosis in a rat experimental subarachnoid hemorrhage model. Cell Mol Neurobiol, 35:543-553.

[234] Wang X, Li S, Ma J, Wang C, Chen A, Xin Z, et al. (2019). Effect of Gastrodin on Early Brain Injury and Neurological Outcome After Subarachnoid Hemorrhage in Rats. Neurosci Bull, 35:461-470.

[235] Cai J, Cao S, Chen J, Yan F, Chen G, Dai Y (2015). Progesterone alleviates acute brain injury via reducing apoptosis and oxidative stress in a rat experimental subarachnoid hemorrhage model. Neurosci Lett, 600:238-243.

[236] Mo J, Enkhjargal B, Travis ZD, Zhou K, Wu P, Zhang $\mathrm{G}$, et al. (2019). AVE 0991 attenuates oxidative stress and neuronal apoptosis via Mas/PKA/CREB/UCP-2 pathway after subarachnoid hemorrhage in rats. Redox Biol, 20:75-86.

[237] Huang CY, Wang LC, Wang HK, Pan CH, Cheng YY, Shan YS, et al. (2015). Memantine alleviates brain injury and neurobehavioral deficits after experimental subarachnoid hemorrhage. Mol Neurobiol, 51:10381052 .

[238] Zhang X, Wu Q, Lu Y, Wan J, Dai H, Zhou X, et al.
(2018). Cerebroprotection by salvianolic acid B after experimental subarachnoid hemorrhage occurs via Nrf2- and SIRT1-dependent pathways. Free Radic Biol Med, 124:504-516.

[239] Zhang XS, Wu Q, Wu LY, Ye ZN, Jiang TW, Li W, et al. (2016). Sirtuin 1 activation protects against early brain injury after experimental subarachnoid hemorrhage in rats. Cell Death Dis, 7:e2416.

[240] Gu X, Zheng C, Zheng Q, Chen S, Li W, Shang Z, et al. (2017). Salvianolic acid A attenuates early brain injury after subarachnoid hemorrhage in rats by regulating ERK/P38/Nrf2 signaling. Am J Transl Res, 9:5643-5652.

[241] Shao J, Wu Q, Lv SY, Zhou XM, Zhang XS, Wen LL, et al. (2019). Allicin attenuates early brain injury after experimental subarachnoid hemorrhage in rats. J Clin Neurosci, 63:202-208.

[242] Zhang T, Wu P, Budbazar E, Zhu Q, Sun C, Mo J, et al. (2019). Mitophagy Reduces Oxidative Stress Via Keap1 (Kelch-Like Epichlorohydrin-Associated Protein 1)/Nrf2 (Nuclear Factor-E2-Related Factor 2)/PHB2 (Prohibitin 2) Pathway After Subarachnoid Hemorrhage in Rats. Stroke, 50:978-988.

[243] Chen J, Wang L, Wu C, Hu Q, Gu C, Yan F, et al. (2014). Melatonin-enhanced autophagy protects against neural apoptosis via a mitochondrial pathway in early brain injury following a subarachnoid hemorrhage. J Pineal Res, 56:12-19.

[244] Huang X, Xiaokaiti Y, Yang J, Pan J, Li Z, Luria V, et al. (2018). Inhibition of phosphodiesterase 2 reverses gp91phox oxidase-mediated depression- and anxietylike behavior. Neuropharmacology, 143:176-185.

[245] Heck SO, Zborowski VA, Quines CB, Nogueira CW (2019). 4,4'-Dichlorodiphenyl diselenide reverses a depressive-like phenotype, modulates prefrontal cortical oxidative stress and dysregulated glutamatergic neurotransmission induced by subchronic dexamethasone exposure to mice. J Psychiatr Res, 116:61-68.

[246] Bukharaeva E, Shakirzyanova A, Khuzakhmetova V, Sitdikova G, Giniatullin R (2015). Homocysteine aggravates ROS-induced depression of transmitter release from motor nerve terminals: potential mechanism of peripheral impairment in motor neuron diseases associated with hyperhomocysteinemia. Front Cell Neurosci, 9:391.

[247] Sepehrmanesh Z, Kolahdooz F, Abedi F, Mazroii N, Assarian A, Asemi Z, et al. (2016). Vitamin D Supplementation Affects the Beck Depression Inventory, Insulin Resistance, and Biomarkers of Oxidative Stress in Patients with Major Depressive Disorder: A Randomized, Controlled Clinical Trial. J Nutr, 146:243-248.

[248] Jiang CY, Qin XY, Yuan MM, Lu GJ, Cheng Y (2018). 2,3,5,4'-Tetrahydroxystilbene-2-O-beta-D-glucoside Reverses Stress-Induced Depression via Inflammatory and Oxidative Stress Pathways. Oxid Med Cell Longev, 2018:9501427.

[249] Athira KV, Madhana RM, Chandran JSI, Lahkar M, Sinha S, Naidu VGM (2018). Antidepressant activity 
of vorinostat is associated with amelioration of oxidative stress and inflammation in a corticosteroneinduced chronic stress model in mice. Behavioural Brain Research, 344:73-84.

[250] Bansal Y, Singh R, Saroj P, Sodhi RK, Kuhad A (2018). Naringenin protects against oxido-inflammatory aberrations and altered tryptophan metabolism in olfactory bulbectomized-mice model of depression. Toxicol Appl Pharmacol, 355:257-268.

[251] Umukoro S, Kalejaye HA, Ben-Azu B, Ajayi AM (2018). Naringenin attenuates behavioral derangements induced by social defeat stress in mice via inhibition of acetylcholinesterase activity, oxidative stress and release of pro-inflammatory cytokines. Biomed Pharmacother, 105:714-723.

[252] Zhao XJ, Zhao Z, Yang DD, Cao LL, Zhang L, Ji J, et al. (2017). Activation of ATP-sensitive potassium channel by iptakalim normalizes stress-induced HPA axis disorder and depressive behaviour by alleviating inflammation and oxidative stress in mouse hypothalamus. Brain Res Bull, 130:146-155.

[253] Thakare VN, Aswar MK, Kulkarni YP, Patil RR, Patel BM (2017). Silymarin ameliorates experimentally induced depressive like behavior in rats: Involvement of hippocampal BDNF signaling, inflammatory cytokines and oxidative stress response. Physiol Behav, 179:401-410.

[254] Chen WJ, Du JK, Hu X, Yu Q, Li DX, Wang CN, et al. (2017). Protective effects of resveratrol on mitochondrial function in the hippocampus improves inflammation-induced depressive-like behavior. Physiol Behav, 182:54-61.

[255] Sulakhiya K, Kumar P, Jangra A, Dwivedi S, Hazarika NK, Baruah CC, et al. (2014). Honokiol abrogates lipopolysaccharide-induced depressive like behavior by impeding neuroinflammation and oxido-nitrosative stress in mice. Eur J Pharmacol, 744:124-131.

[256] Weckmann K, Deery MJ, Howard JA, Feret R, Asara JM, Dethloff F, et al. (2017). Ketamine's antidepressant effect is mediated by energy metabolism and antioxidant defense system. Scientific Reports, 7.

[257] Berkiks I, Benmhammed H, Mesfioui A, Ouichou A, El Hasnaoui A, Mouden S, et al. (2018). Postnatal melatonin treatment protects against affective disorders induced by early-life immune stimulation by reducing the microglia cell activation and oxidative stress. Int J Neurosci, 128:495-504.

[258] Wang Y, Zhao S, Liu X, Zheng Y, Li L, Meng S (2018). Oxytocin improves animal behaviors and ameliorates oxidative stress and inflammation in autistic mice. Biomed Pharmacother, 107:262-269.

[259] Ben Saad H, Kharrat N, Driss D, Gargouri M, Marrakchi R, Jammoussi K, et al. (2017). Effects of vanillin on potassium bromate-induced neurotoxicity in adult mice: impact on behavior, oxidative stress, genes expression, inflammation and fatty acid composition. Arch Physiol Biochem, 123:165-174.

[260] Khalili M, Alavi M, Esmaeil-Jamaat E, Baluchnejadmojarad T, Roghani M (2018).
Trigonelline mitigates lipopolysaccharide-induced learning and memory impairment in the rat due to its anti-oxidative and anti-inflammatory effect. Int Immunopharmacol, 61:355-362.

[261] Mehta V, Parashar A, Udayabanu M (2017). Quercetin prevents chronic unpredictable stress induced behavioral dysfunction in mice by alleviating hippocampal oxidative and inflammatory stress. Physiol Behav, 171:69-78.

[262] Herbet M, Izdebska M, Pidtkowska-Chmiel I, Gawronska-Grzywacz M, Natorska-Chomicka D, Pawlowski K, et al. (2018). alpha-Tocopherol Ameliorates Redox Equilibrium and Reduces Inflammatory Response Caused by Chronic Variable Stress. Biomed Research International.

[263] Zhong J, Li G, Xu H, Wang Y, Shi M (2019). Baicalin ameliorates chronic mild stress-induced depressionlike behaviors in mice and attenuates inflammatory cytokines and oxidative stress. Braz J Med Biol Res, 52:e8434.

[264] Casaril AM, Domingues M, Bampi SR, de Andrade Lourenco D, Padilha NB, Lenardao EJ, et al. (2019). The selenium-containing compound 3-((4chlorophenyl)selanyl)-1-methyl-1H-indole reverses depressive-like behavior induced by acute restraint stress in mice: modulation of oxido-nitrosative stress and inflammatory pathway. Psychopharmacology (Berl).

[265] Abdallah CG, De Feyter HM, Averill LA, Jiang L, Averill CL, Chowdhury GMI, et al. (2018). The effects of ketamine on prefrontal glutamate neurotransmission in healthy and depressed subjects. Neuropsychopharmacology, 43:2154-2160.

[266] Du RH, Wu FF, Lu M, Shu XD, Ding JH, Wu G, et al. (2016). Uncoupling protein 2 modulation of the NLRP3 inflammasome in astrocytes and its implications in depression. Redox Biol, 9:178-187.

[267] Yang M, Dang R, Xu P, Guo Y, Han W, Liao D, et al. (2018). Dl-3-n-Butylphthalide improves lipopolysaccharide-induced depressive-like behavior in rats: involvement of Nrf2 and NF-kappaB pathways. Psychopharmacology (Berl), 235:2573-2585.

[268] El-Naga RN, Ahmed HI, Abd Al Haleem EN (2014). Effects of indole-3-carbinol on clonidine-induced neurotoxicity in rats: Impact on oxidative stress, inflammation, apoptosis and monoamine levels. Neurotoxicology, 44:48-57.

[269] Shal B, Khan A, Naveed M, Ullah Khan N, Ihsan Ul H, S DA, et al. (2019). Effect of 25-methoxy hispidol A isolated from Poncirus trifoliate against bacteriainduced anxiety and depression by targeting neuroinflammation, oxidative stress and apoptosis in mice. Biomed Pharmacother, 111:209-223.

[270] Gao W, Wang W, Liu G, Zhang J, Yang J, Deng Z (2019). Allicin attenuated chronic social defeat stress induced depressive-like behaviors through suppression of NLRP3 inflammasome. Metab Brain Dis, 34:319-329.

[271] Li X, Wu T, Yu Z, Li T, Zhang J, Zhang Z, et al. (2018). Apocynum venetum leaf extract reverses depressive- 
like behaviors in chronically stressed rats by inhibiting oxidative stress and apoptosis. Biomed Pharmacother, 100:394-406.

[272] Tang ZY, Li M, Zhang XW, Hou WS (2016). Dietary flavonoid intake and the risk of stroke: a doseresponse meta-analysis of prospective cohort studies. Bmj Open, 6.

[273] Bao D, Wang J, Pang X, Liu H (2017). Protective Effect of Quercetin against Oxidative Stress-Induced Cytotoxicity in Rat Pheochromocytoma (PC-12) Cells. Molecules, 22.

[274] Alam F, Saqib QN, Ashraf M (2017). Gaultheria trichophylla (Royle): a source of minerals and biologically active molecules, its antioxidant and antilipoxygenase activities. BMC Complement Altern Med, 17:3.

[275] Carradori S, Gidaro MC, Petzer A, Costa G, Guglielmi P, Chimenti P, et al. (2016). Inhibition of Human Monoamine Oxidase: Biological and Molecular Modeling Studies on Selected Natural Flavonoids. J Agric Food Chem, 64:9004-9011.

[276] Chang SC, Cassidy A, Willett WC, Rimm EB, O'Reilly EJ, Okereke OI (2016). Dietary flavonoid intake and risk of incident depression in midlife and older women. Am J Clin Nutr, 104:704-714.

[277] Chamorro A, Amaro S, Castellanos M, Segura T, Arenillas J, Marti-Fabregas J, et al. (2014). Safety and efficacy of uric acid in patients with acute stroke (URICO-ICTUS): a randomised, double-blind phase 2b/3 trial. Lancet Neurol, 13:453-460.

[278] Llull L, Laredo C, Renu A, Perez B, Vila E, Obach V, et al. (2015). Uric Acid Therapy Improves Clinical Outcome in Women With Acute Ischemic Stroke. Stroke, 46:2162-2167.

[279] Amaro S, Llull L, Renu A, Laredo C, Perez B, Vila E, et al. (2015). Uric acid improves glucose-driven oxidative stress in human ischemic stroke. Ann Neurol, 77:775-783

[280] Wium-Andersen MK, Kobylecki CJ, Afzal S, Nordestgaard BG (2017). Association between the antioxidant uric acid and depression and antidepressant medication use in 96989 individuals. Acta Psychiatrica Scandinavica, 136:424-433.

[281] Bartoli F, Trotta G, Crocamo C, Malerba MR, Clerici $\mathrm{M}$, Carra G (2018). Antioxidant uric acid in treated and untreated subjects with major depressive disorder: a meta-analysis and meta-regression. Eur Arch Psychiatry Clin Neurosci, 268:119-127.

[282] Aly H, Elmandy H, El-Dib M, Rowisha M, Awny M, El-Gohary $\mathrm{T}$, et al. (2015). Melatonin use for neuroprotection in perinatal asphyxia: a randomized controlled pilot study. Journal of Perinatology, 35:186191.

[283] Targum SD, Wedel PC, Fava M (2015). Changes in cognitive symptoms after a buspirone-melatonin combination treatment for Major Depressive Disorder. J Psychiatr Res, 68:392-396.

[284] Villa RF, Ferrari F, Moretti A (2018). Post-stroke depression: Mechanisms and pharmacological treatment. Pharmacol Ther, 184:131-144.
[285] Collaboration FT (2019). Effects of fluoxetine on functional outcomes after acute stroke (FOCUS): a pragmatic, double-blind, randomised, controlled trial. Lancet, 393:265-274.

[286] Sun Y, Liang Y, Jiao Y, Lin J, Qu H, Xu J, et al. (2017). Comparative efficacy and acceptability of antidepressant treatment in poststroke depression: a multiple-treatments meta-analysis. BMJ Open, 7:e016499.

[287] Chollet F, Tardy J, Albucher JF, Thalamas C, Berard E, Lamy C, et al. (2011). Fluoxetine for motor recovery after acute ischaemic stroke (FLAME): a randomised placebo-controlled trial. Lancet Neurol, 10:123-130.

[288] Kim JS (2017). Management of post-stroke mood and emotional disturbances. Expert Rev Neurother, 17:1179-1188.

[289] Kim JS, Lee EJ, Chang DI, Park JH, Ahn SH, Cha JK, et al. (2017). Efficacy of early administration of escitalopram on depressive and emotional symptoms and neurological dysfunction after stroke: a multicentre, double-blind, randomised, placebocontrolled study. Lancet Psychiatry, 4:33-41.

[290] Robinson RG, Jorge RE, Moser DJ, Acion L, Solodkin A, Small SL, et al. (2008). Escitalopram and problemsolving therapy for prevention of poststroke depression: a randomized controlled trial. JAMA, 299:2391-2400.

[291] Savadi Oskouie D, Sharifipour E, Sadeghi Bazargani H, Hashemilar M, Nikanfar M, Ghazanfari Amlashi S, et al. (2017). Efficacy of Citalopram on Acute Ischemic Stroke Outcome: A Randomized Clinical Trial. Neurorehabil Neural Repair, 31:638-647.

[292] Kraglund KL, Mortensen JK, Grove EL, Johnsen SP, Andersen G (2015). TALOS: a multicenter, randomized, double-blind, placebo-controlled trial to test the effects of citalopram in patients with acute stroke. Int J Stroke, 10:985-987.

[293] Mortensen JK, Larsson H, Johnsen SP, Andersen G (2014). Impact of prestroke selective serotonin reuptake inhibitor treatment on stroke severity and mortality. Stroke, 45:2121-2123.

[294] Tsai CS, Wu CL, Chou SY, Tsang HY, Hung TH, Su JA (2011). Prevention of poststroke depression with milnacipran in patients with acute ischemic stroke: a double-blind randomized placebo-controlled trial. Int Clin Psychopharmacol, 26:263-267.

[295] Ferro JM, Caeiro L, Figueira ML (2016). Neuropsychiatric sequelae of stroke. Nat Rev Neurol, 12:269-280.

[296] Guiraud V, Gallarda T, Calvet D, Turc G, Oppenheim C, Rouillon F, et al. (2016). Depression predictors within six months of ischemic stroke: The DEPRESS Study. International Journal of Stroke, 11:519-525.

[297] Sweeney MD, Zhao Z, Montagne A, Nelson AR, Zlokovic BV (2019). Blood-Brain Barrier: From Physiology to Disease and Back. Physiol Rev, 99:2178.

[298] Tang Z, Li M, Zhang X, Hou W (2016). Dietary flavonoid intake and the risk of stroke: a doseresponse meta-analysis of prospective cohort studies. 
BMJ Open, 6:e008680.

[299] De Crescenzo F, Lennox A, Gibson JC, Cordey JH, Stockton S, Cowen PJ, et al. (2017). Melatonin as a treatment for mood disorders: a systematic review. Acta Psychiatr Scand, 136:549-558.

[300] Valko M, Leibfritz D, Moncol J, Cronin MTD, Mazur M, Telser J (2007). Free radicals and antioxidants in normal physiological functions and human disease. International Journal of Biochemistry \& Cell Biology, 39:44-84.

[301] Forrester SJ, Kikuchi DS, Hernandes MS, Xu Q, Griendling KK (2018). Reactive Oxygen Species in
Metabolic and Inflammatory Signaling. Circ Res, 122:877-902.

[302] Serrander L, Cartier L, Bedard K, Banfi B, Lardy B, Plastre O, et al. (2007). NOX4 activity is determined by mRNA levels and reveals a unique pattern of ROS generation. Biochemical Journal, 406:105-114.

[303] Saso L, Firuzi O (2014). Pharmacological applications of antioxidants: lights and shadows. Curr Drug Targets, 15:1177-1199.

[304] Khey KMW, Huard A, Mahmoud SH (2019). Inflammatory Pathways Following Subarachnoid Hemorrhage. Cell Mol Neurobiol. 